\title{
Small molecule biomarkers in Alzheimer's disease
}

\author{
Min $\operatorname{Kim}^{1,2}$ and Cristina Legido-Quigley ${ }^{1,2, *}$ \\ ${ }^{1}$ Institute of Pharmaceutical Science, King's College London, London, UK \\ 2 Steno Diabetes Center Copenhagen, Gentofte, Denmark
}

Received 6 February 2018 - Accepted 3 April 2018

\begin{abstract}
Alzheimer's disease (AD) is a progressive neurodegenerative disease which affects a growing number of people as the population ages worldwide. Alzheimer's Disease International estimated that more than 100 million people will be living with dementia by 2050. At present there are no disease-modifying therapies and research has expanded to the -omic sciences with scientists aiming to get a holistic view of the disease using systems medicine. Metabolomics and Lipidomics give a snap-shot of the metabolism. As analyzing the brain in vivo is difficult, the metabolic information of the periphery has potential to unravel mechanisms that have not been considered, such as those that link the brain to the liver and the gut or other organs. With that in mind we have produced a mini-review, to record a number of studies in the field and the molecular pathways that have been flagged in animal and human models of AD. Human studies deal with cohorts in the order of the hundreds due to the difficulty of organizing AD studies, however it is possible that these first pilots point towards important mechanisms. The trend in these small studies is the involvement of many organs and pathways. Some findings, that have been reproduced, are ceramides being increased, phospholipids and neurotransmitters depleted and sterols being found depleted too. Initial findings point to an important role to lipid homeostasis in $\mathrm{AD}$, this is not surprising as the brain's main constituents are water and lipids.
\end{abstract}

Keywords: Alzheimer's disease / metabolomics / lipidomics / biomarker

Résumé - Biomarqueurs à petites molécules dans la maladie d'Alzheimer. La maladie d'Alzheimer est une maladie neurodégénérative progressive qui affecte un nombre croissant de personnes en raison du vieillissement de la population observé dans le monde entier. La fédération internationale d'associations Alzheimer's disease International estime que plus de 100 millions de personnes vivront avec cette démence d'ici à 2050. Il n'existe actuellement aucun traitement de la maladie et la recherche s'est élargie aux sciences -omiques avec l'objectif scientifique d'obtenir une approche globale de la maladie en utilisant une médecine des systèmes. La métabolomique et la lipidomique donnent un aperçu du métabolisme. L'analyse du cerveau in vivo s'avérant difficile, l'information métabolique de la périphérie possède le potentiel de démêler des mécanismes qui n'ont pas été pris en compte, tels que ceux reliant le cerveau au foie et à l'intestin ou à d'autres organes. Dans cet esprit, nous proposons une mini-revue, afin de lister un certain nombre d'études relevant de ce champ et les voies moléculaires qui ont été signalées chez les modèles animaux et humains de la maladie d'Alzheimer. Les études humaines traitent des cohortes de quelque centaines d'individus en raison de la difficulté à organiser des études sur cette pathologie, mais il est possible que ces premiers pilotes pointent vers des mécanismes importants. La tendance dans ces petites études est l'implication de nombreux organes et voies. Certaines conclusions, qui ont été reproduites, indiquent que les céramides sont augmentées, les phospholipides et les neurotransmetteurs appauvris et les stérols également épuisés. Les premiers résultats indiquent un important rôle de l'homéostasie des lipides dans la maladie d'Alzheimer, ce qui ne semble guère surprenant puisque les principaux constituants du cerveau sont l'eau et les lipides.

Mots clés : maladie d'Alzheimer / métabolomique / lipidomique / biomarqueur

*Correspondence: cristina.legido.quigley@regionh.dk 


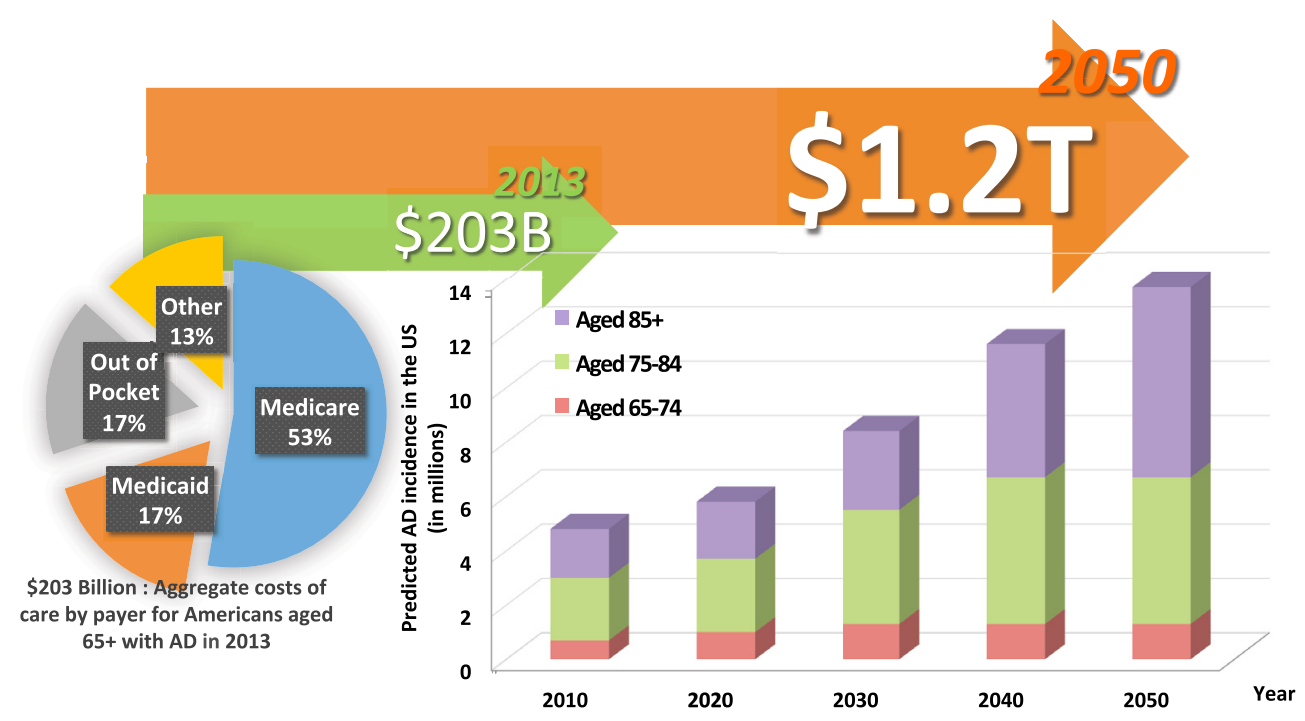

Fig. 1. Alzheimer's projection on incidence cost of Alzheimer's care. Pie chart shows the breakdown of aggregate cost of care in the US. Data drawn from (Alzheimer's, 2015, Hebert et al., 2013, Thies et al., 2013).

\section{Introduction}

Alzheimer's disease (AD) is a progressive neurodegenerative disorder characterized with memory impairment and personality behavior changes, caused by gradual brain cell apoptosis. It is the most common form of dementia accounting for $50 \%$ to $70 \%$ of cases. Other dementias include Lewy body disease (LBD), frontotemporal dementia (FTD), vascular dementia (VAD) and Parkinson's' disease (PD). In some cases, patients can be diagnosed with a combination of two or more dementias.

$\mathrm{AD}$ can present in two forms, early-onset $\mathrm{AD}$ (EOAD) and late-onset $\mathrm{AD}$ (LOAD). This report will mainly focus on LOAD. Incidence of LOAD normally occurs in people of 65 or older, it has no clear familial pattern and it is considered sporadic (sporadic AD). EOAD occurs before the age of 65 (mean age of 46 years old, but can appear as early as 30 s) (Ryman et al., 2014) and it accounts for less than 1\% of all AD cases. EOAD is largely hereditary and genetic mutation is the biggest risk factor. EOAD has association with these deterministic variations and it can be called autosomal dominant $\mathrm{AD}$ (ADAD, also termed familial AD).

Currently AD is the $6^{\text {th }}$ leading cause of death and the $3^{\text {rd }}$ leading cause of death among people aged 65 or older in the United States (US) (James et al., 2014). Despite this, there is currently no treatment for the disease. The estimated incidence of $\mathrm{AD}$ is only likely to increase due to the rapid increase in number of elders. Current estimates suggest AD incidence will increase from 5.4 million (2016) to 13.7 million (2050) in the US (Hebert et al., 2013; Alzheimer's, 2015).

The progress of $\mathrm{AD}$ is relatively slow; people often live on average 4 to 6 years after diagnosis and some can live as long as 20 years. People with $\mathrm{AD}$ require partial or full assistance and patients lose ability to take care of their other chronic health problems, such as diabetes or heart disease. All of these factors contribute in making $\mathrm{AD}$ an expensive disease. In the US, the disease was reported to cost \$226 billion in 2012, and this cost is predicted to increase to $\$ 1.2$ trillion by 2050 (Alzheimer's, 2015).

Despite these facts (summarized in Fig. 1), the reality is that the disease mechanism is not comprehensively understood; definite $\mathrm{AD}$ diagnosis can only be made on post-mortem brains, and there is no AD prevention or treatment therapies. Currently, just a few drugs are available for $\mathrm{AD}$ patients and they are only able to slow the progression of symptoms. Therefore, it is vitally important to determine the biochemistry behind $\mathrm{AD}$, and develop tools for $\mathrm{AD}$ diagnosis, treatment and prevention.

\section{Current markers of AD}

The AD diagnosis criteria was set up by NINDS-ADRA in 1984 and was reported to have average sensitivity and specificity of $81 \%$ and $70 \%$ respectively (Knopman et al., 2001). This meant that some individuals were identified to having $\mathrm{AD}$ when in fact they were non- $\mathrm{AD}$ dementia. A recent guideline set up by NIA-AA in 2011 recommended measurements of $A \beta$ and tau (brain and CSF) as diagnostic adjuncts to achieve better $\mathrm{AD}$ diagnostic accuracy. These criteria also defined individuals in pre-clinical AD and/or MCI stages (McKhann et al., 2011). As the result, the following tests can be employed to aid AD diagnosis (Tab. 1) and are often termed AD biomarkers.

A biomarker is defined by the U.S. National Institutes of Health Biomarkers Definitions Working Group as "a characteristic that is objectively measured and evaluated as an indicator of normal biological processes, pathogenic process, or pharmacologic responses to a therapeutic intervention" (Atkinson et al., 2001). Biomarkers allow clinicians to evaluate the state of an individual's health; confirm disease onset and progression; or gauge whether a treatment is working or not. They must display high sensitivity and specificity, while ease-of use is also an important factor to be defined as biomarkers. (Desai and Grossberg, 2005; Hampel 
Table 1. Classification of biomarkers used in the differential diagnosis of $\mathrm{AD}$. These markers are recommended by NIA-AA.

\begin{tabular}{ll}
\hline Biomarkers for AD & $\begin{array}{l}\text { Pathophysiological } \\
\text { correlate }\end{array}$ \\
\hline $\begin{array}{l}\text { Neuropsychological } \\
\text { Tests for episodic memory } \\
\text { /delayed recall } \\
\text { Cerebrospinal fluid }\end{array}$ & $\begin{array}{l}\text { Hippocampal amnesia } \\
\text { due to AD }\end{array}$ \\
A $\beta 42$ & Neuronal A $\beta$ plaque \\
Total-tau & $\begin{array}{l}\text { accumulation } \\
\text { Phosphorylated tau }\end{array}$ \\
Amyloid Imaging & Intra neuronal NFT \\
A $\beta$ PET & Neuronal A $\beta$ plaque \\
Structural neuroimaging & accumulation \\
Magnetic resonance imaging (MRI) & Neuronal injury marker \\
Computed tomography (CT) & Neuronal injury marker \\
Functional neuroimaging & Glucose hypometabolism \\
FDG-PET &
\end{tabular}

et al., 2010; Humpel, 2011). Examples include body temperature for fever, blood pressure for the risk of stroke, cholesterol values for coronary and vascular diseases, and $\mathrm{C}$ reactive protein (CRP) for inflammation.

As shown in Table 1, AD biomarkers are mainly based on measurements of $A \beta$ and tau and allow relatively high $A D$ diagnosis accuracy (Harris et al., 2015). In particular, CSF $\mathrm{A} \beta_{42}$, total- and phosphor- tau measurements can detect individuals in preclinical stage of $\mathrm{AD}$, and therefore have an ability of predicting the risk of progression to AD. However, these markers are the subject of debate for a number of reasons. PET imaging is expensive while lumbar puncture for CSF collection is invasive. Most importantly, DMT drugs directed toward attenuating the $A \beta$ and tau pathways have all failed to show positive results during clinical trials (Cummings et al., 2016). As a result, focus in $A D$ research has shifted towards early intervention and prevention of AD. Also, the scientific community believe that pathology other than amyloid and tau needs to be targeted (Dong et al., 2012; Reitz, 2012) as well as a need to discover new biomarkers which would recognise individuals in the asymptomatic (preclinical) stage.

A test with biomarkers would benefit $\mathrm{AD}$ patients in a number of ways, it would distinguish AD from other types of dementia and allow more accurate treatment to be initiated (Humpel, 2011). It can potentially identify novel mechanistic pathways of the disease and consequently set the path for the discovery of a disease-modifying drug. Conversely, biomarkers would allow the correct selection of people in a preclinical stage of $\mathrm{AD}$ for clinical trials and help with prevention therapies (Fiandaca et al., 2014).

Finding biomarkers of Alzheimer's disease is a priority in the medical research field, especially biomarkers for the preclinical and clinical stages of AD. This has involved assays of blood (Hye et al., 2014; Mapstone et al., 2014), skin (Khan and Alkon, 2010), urine (Ghanbari et al., 1998), hair (Son et al., 2016), odour (Kimball et al., 2016a), and olfactory deficits (Tabert et al., 2005) with candidates being proteins, genes, clinical symptoms or small metabolites. Of these, peripheral blood has been the most extensively interrogated, as it is accessible by minimally invasive means and offers a relatively inexpensive substrate for analysis. Also crucially, blood is comprised of a liquid component (plasma or serum) and a wide variety of cells (mononuclear leukocytes, erythrocytes and platelets). The liquid component is often used for proteins or small molecules profiling; Ribonucleic Acid (RNA) assay can be obtained from cells (and serum and plasma exosomes). This particular nature of blood therefore represents a unique opportunity for biomarker discovery and development.

For discovery of novel blood-based biomarkers of AD, a wide array of technological platforms have been applied in recent years. For example, application of Polymerase Chain Reaction (PCR) has proposed circulating microRNAs (Kumar et al., 2013; Tan et al., 2014); the most promising result showed a panel of 12 microRNAs which differentiated AD from controls with accuracy of 93\% (Leidinger et al., 2013). Transcriptomic tests have also been applied on blood; a signature consisting of 170 probe sets has been identified to discriminate AD from controls with sensitivity and specificity of $81.3 \%$ and $67.1 \%$ respectively (Fehlbaum-Beurdeley et al., 2012).

A wide number of studies have also focused on bloodbased proteomic biomarkers of $\mathrm{AD}, \mathrm{A} \beta$ being the initial focus. Cross-sectional studies comparing levels of blood $A \beta$ in $A D$ have not shown consistent results; negative (Blennow et al., 2010; Toledo et al., 2013; Snyder et al., 2014; Janelidze et al., 2016) as well as positive (Lopez et al., 2008; Mayeux et al., 2003; Lambert et al., 2009) test results have been reported. Several other proteins have also been proposed; Ray et al. described a panel of 18 proteins being able to predict AD from controls with $90 \%$ accuracy (Ray et al., 2007a) while glycan signatures have shown to discriminate with a sensitivity and specificity of $89.3 \%$ and $79.1 \%$ respectively (Lundstrom et al., 2014). Recently, O’Bryant et al., (2016) established a 21 protein panel as an AD discriminator in $n=1329$ study; the sensitivity and specificity were $63 \%$ and $98 \%$ respectively. Other groups have also looked at potential preclinical AD biosignatures. A panel of 25 proteins was found to predict conversion of AD from controls with sensitivity of $80 \%$ and specificity of $91 \%$ (O'Bryant et al., 2010) while 10 plasma proteins were found to predict progression to $\mathrm{AD}$ from $\mathrm{MCI}$ (accuracy 87\%) (Hye et al., 2014). Another promising crosssectional study showed 18 proteins being able to predict conversion from symptomatic MCI to AD with accuracy of 91\% (Ray et al., 2007b); successive validation studies failed to replicate (Soares et al., 2009; Marksteiner et al., 2011).

\section{Lipidomics and metabolomics}

The last decades have seen much advancement in analytical technologies such as nuclear magnetic resonance (NMR) and high-resolution tandem mass spectrometry (MS). One of the many applications of this technology is the accurate detection and fingerprinting or profiling of small molecule metabolites $(<1500 \mathrm{Da})$. The field where as many small 


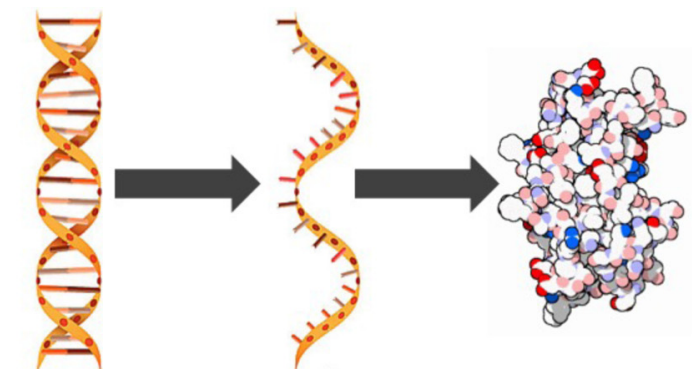

Genes (Genomes)

RNA

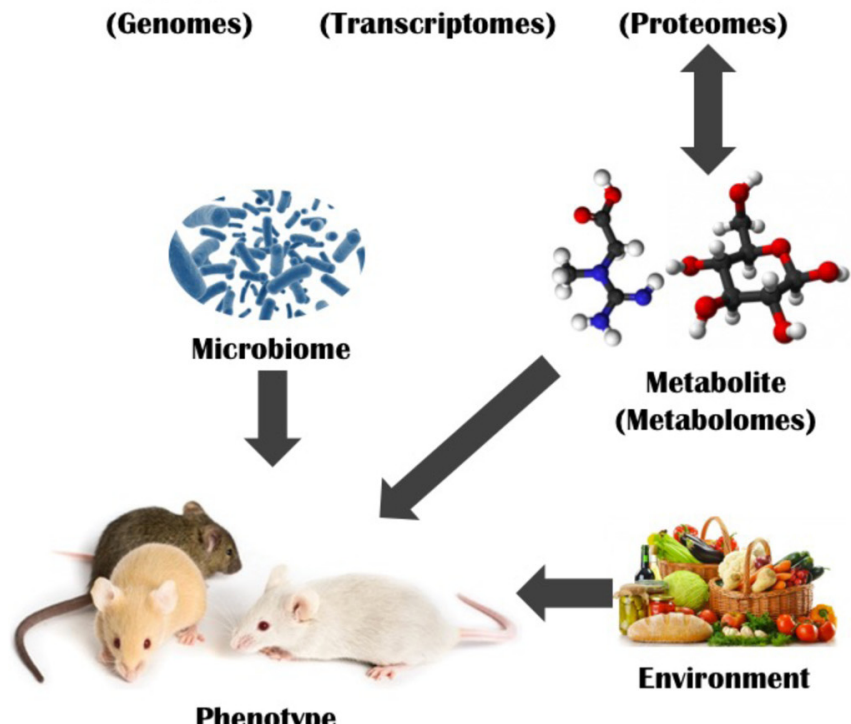

Phenotype

Fig. 2. A schematic diagram of a systems approach to biology. The diagram shows that metabolites are the terminal downstream products of genomes, transciptomes, and proteomes in the whole organisms.

molecules are measured is often termed as 'metabolomics' or sometimes 'metabonomics'.

Metabolomics involves a comprehensive and simultaneous systematic profiling of metabolite concentrations and their fluctuation that reflects in response of living systems to pathophysiological stimuli and/or genetic modifications and the surrounding environment (Beckonert et al., 2007; Want et al., 2010; Wilson, 2011). Metabonomics is another term often used interchangeably with metabolomics as the analytical and modeling procedures are the same. Metabolomics can be categorized into two distinct approaches, classically it is non-targeted (or untargeted), but it is also possible to analyse a chosen panel of metabolites and call it targeted metabolomics. The non-targeted approach involves quantification/relative-quantification of as many as possible metabolites in a biological system. Targeted approach is where chemically characterized and biochemically annotated metabolites are quantified using specific methodologies designed with a target in mind (Roberts et al., 2012).

Metabolomics has a number of inherent advantages compared to the use of other profiling techniques such as genomics and proteomics. Since metabolites are the terminal downstream product of the genome, monitoring the perturbations in a pool of metabolites could reflect underlying disease pathology and further, disease prognosis and diagnosis
(Fig. 2). Also, metabolomics can react very fast to stimuli or to change, therefore it is capable of viewing the most current view of the system's biology. Through evolution, metabolic pathways have been conserved, which means metabolic pathways are similar in rodent and humans. Therefore, metabolic signatures identified in mechanistic and therapeutic studies for animal models can in theory be translated into human studies (Holmes and Nicholson, 2007). Moreover, metabolomics is relatively inexpensive and time efficient when compared to genomics or proteomics, and can be applied to variety of easily accessible biofluids such as plasma, CSF, urine, and peripheral tissues, thus highlighting the clinical utility of the approach (Nicholson et al., 2007).

The overall size of the metabolome remains elusive in metabolomics field, but it is estimated to range from a few thousands to hundreds of thousands of small molecules (Wishart et al., 2009; Psychogios et al., 2011). Recent advancements in analytical technologies have allowed measurements of dynamic changes in many molecules in biological samples simultaneously. These technologies include high-resolution NMR and MS coupled with chromatographic techniques. However, no analytical techniques is available for the analysis of the entire metabolome content. Often a range of criteria such as speed, cost, properties of the analytes, sensitivity and the choice of biofluid needs to be considered.

\section{Lipid metabolism}

Implication of altered lipid metabolism in $\mathrm{AD}$ pathogenesis was first suggested by Alois Alzheimer (Sparks et al., 1994; Foley, 2010), but this hypothesis has been gaining acceptability only in recent years (Proitsi et al., 2014; Djelti et al., 2015), after the discovery of $\varepsilon 4$ allele of the apolipoprotein $\mathrm{E}$ (ApoE) gene being the strongest LOAD genetic risk factor (Corder et al., 1993; Bertram and Tanzi, 2008). Implication of lipids in $\mathrm{AD}$ is perhaps logical considering all enzymes involved in amyloidogenic pathway (APP, $\beta$-secretase and $\gamma$-secretase) are transmembrane proteins. A perturbed lipid bilayer composition and organization will impact on trafficking and/or proteolytic activity of these transmembrane proteins, and thus APP processing and A $\beta$ production (Hartmann et al., 2007).

Of all lipid classes, high cholesterol levels in brain (cholesterol homeostasis) has been implicated with AD the most. Cholesterol has an essential role in the brain, helping to maintain neuronal functions such as neurotransmitter release and synaptic plasticity (Koudinov and Koudinova, 2001; Linetti et al., 2010). However, when cholesterol is in excess in the brain (de novo), it is esterified into cholesteryl esters by acyl-cholesterol-acyltransferase-1 (ACAT1), and accumulation of this intracellular cholesteryl ester can enhance $A \beta$ release (Puglielli et al., 2001; Di Paolo and Kim, 2011). Supporting this hypothesis, pharmacological inhibition of ACAT1 has been found to reduce both $A \beta$ production and cholesteryl esters (Bhattacharyya and Kovacs, 2010; Hutter-Paier et al., 2010). Additionally, cholesterol is known to modulate $\beta$-secretase and $\gamma$-secretase activities directly, with a rich environment of cholesterol having been found to accelerate $\mathrm{A} \beta$ deposition (Simons et al., 1998; Wahrle et al., 2002; Vetrivel and Thinakaran, 2010). 
Supporting these biochemical studies are case-control studies where statins, cholesterol-lowering drugs, have been found associating with lower risk of $\mathrm{AD}$ development (Jick et al., 2000; Wolozin et al., 2007). Statin has also shown to promote ectodomain (domain of a membrane protein that extends into extracellular space) shedding of APP through the $\alpha$-secretase pathway (non-amyloidogenic pathway), inhibiting $\mathrm{A} \beta$ production in a cholesterol-independent manner (Pedrini et al., 2005). However, retrospective clinical trials involving a prospective cohort have shown conflicting results, Wolozin et al. (2007) reported lower incidence of the dementia while Arvanitakis et al. (2008) showed no relationship between statin medication and $\mathrm{AD}$ incidence, cognitive decline and $\mathrm{AD}$ pathologies. Additionally, epidemiological studies testing associations between low-density lipoprotein (LDL) cholesterol (often referred as 'bad' cholesterol) and AD have also produced mixed results. While increased levels of total cholesterol levels have been found in post-mortem AD brains (Kuo et al., 1998) and associated with higher AD risk (Kivipelto et al., 2002; Whitmer et al., 2005), no relationship (Tan et al., 2003) or the opposite relationship (Reitz et al., 2004; Mielke et al., 2005; Snowden et al., 2017) have also been reported.

In brain, ApoE is the predominant apolipoprotein (Liu et al., 2013). Interestingly, $A p o E$ is also involved in $A \beta$ clearance (Kim et al., 2009). The activity of ApoE is greatly dependent on its lipidation level, regulated by adenosine triphosphate binding cassette A1 (ABCA1). Immunochemical studies have demonstrated that the lack of ABCA1 results in deficient lipidation of $\mathrm{ApoE}$ and consequently leads to accumulation of amyloid plaques burden, indicating poorly lipidated ApoE to be associated with amyloidogenic pathway (Hirsch-Reinshagen et al., 2005; Koldamova et al., 2005; Wahrle et al., 2005). Additionally, the effect of ApoE seems to be isoform-dependent; $\varepsilon 4$ allele of ApoE results in the highest $\mathrm{A} \beta$ deposition $(\varepsilon 4>\varepsilon 3>\varepsilon 2$ ) (Sepehrnia et al., 1989; Farrer et al., 1997; Kok et al., 2009). However, the mechanism by which ApoE alleles differentially modulate the amyloidogenic pathway is less clear.

In addition to cholesterol, sphingolipids have been found to play a role in $A \beta$ production. Sphingolipids include ceramide, sphingomyeline and glycosphingolipids, and are believed to play important roles in signal transmission and cell recognition (Ohanian and Ohanian, 2001; Hannun and Obeid, 2002). Ceramide, a central component in sphingolipid metabolism, has been suggested to facilitate the regulation of BACEmedicated processing of APP by prolonging the half-life of BACE (Puglielli et al., 2003). Furthermore, these lipid species have been found to mediate oxidative stress-induced neuronal apoptosis, independently of its role in BACE activity regulation (Spiegel and Milstien, 1995; Spiegel and Milstien, 2002; Cutler et al., 2004; He et al., 2010). They have shown to activate enzymes involved in cell apoptosis raging from protein kinase (Lozano et al., 1994), cathepsin D (Heinrich et al., 1999) and serine/threonine protein phosphatase (Dobrowsky et al., 1993). These findings are supported by retrospective epidemiologic studies where high ceramide levels have been found in AD blood (Han XL et al., 2011), CSF (Satoi et al., 2005) and brain (Filippov et al., 2012), while higher serum ceramide levels have also been associated with
AD incidence (Mielke et al., 2012). These findings suggest potential of ceramide-based therapeutic treatments for delaying $\mathrm{AD}$ development. Inhibition of sphingomyelinase (SMase), a catalyst involved in sphingomyeline to ceramide conversion, has been suggested as a therapeutic agent. In addition, neutral SMase (N-SMase) knout out mice has shown lower activation of pro-inflammatory enzymes and subsequently greater protection of neurons (Jana and Pahan, 2010). Dinkins et al., (2014) have also demonstrated that by inhibiting N-SMase activity they observed lower brain ceramide levels and $\mathrm{A} \beta_{42}$ burden.

Phospholipids are another family of lipid species to be associated with $\mathrm{AD}$ along with enzymes involved in phospholipid metabolism. A number of case-control studies have reported abnormal phospholipids levels in AD individuals, namely, lower levels for phosphatidylinositol (PI) (Prasad et al., 1998; Stokes and Hawthorne, 1987; Pettegrew et al., 2001), for phosphatidylethanolamine (PE) (Nitsch et al., 1992; Guan et al., 1999; Prasad et al., 1998) and for phosphatidylcholine (PC) (Nitsch et al., 1992; Wells et al., 1995; Prasad et al., 1998; Guan et al., 1999) in AD brain and in AD blood (Mapstone et al., 2014; Whiley et al., 2014) while they were found increased in AD CSF (Mulder et al., 2003; Walter et al., 2004). Phospholipids are a major component of the cell membrane and play important roles in cellular functions, such as extracellular receptor signalling, intercellular second messengers and cellular pressure regulation (Lutjohann et al., 2012).

\section{Applications of lipidomics/metabolomics in $A D$}

Although metabolomics is a relatively young 'omic' field, in recent years, an extensive number of studies have applied this approach to establish differences in metabolite levels between cognitively normal $(\mathrm{CN})$ individuals and $\mathrm{AD}$ patients. Various biological matrices have been investigated; CSF is very useful due to its composition reflecting in part brain metabolic production. Non-invasive samples such as blood (serum or plasma), urine and saliva have also been analysed with the aim to identify more accessible biomarkers translatable to the clinical practice. Brain is also another source but the focus mainly has been the in situ characterization of neuropathology. Animal model and human AD studies utilizing metabolomics will be discussed in the following section.

\subsection{Animal models of AD}

Metabolomic techniques have been utilized in animal models of $\mathrm{AD}$. With regards to the animal models, it is important to note that the commonly employed transgenic $(\mathrm{Tg})$ animal models are based on over-expression of APP $\left(\mathrm{APP}_{\mathrm{Tg} 2576}, \mathrm{APP}_{\mathrm{V} 717 \mathrm{~F}}\right.$ and CRND8 transgenic lines). Some models also co-express the mutated human presenilin 1 (PSEN1) or presenilin 2 (PSEN2) allowing accelerated amyloid deposition (APP $\times$ PS1 or APP $\times$ PS2 double transgenic models respectively). TASTPM is another double transgenic mouse model carrying two mutations associated with APP and PSEN1. SAMP8 is another model which has 
been frequently used as this model displays a phenotype of accelerated aging and thus age-associated increase in hippocampal $\mathrm{A} \beta$ and age-associated behavioural impairments. These animal models are more closely associated with familial form of $\mathrm{AD}$ rather than $\mathrm{LOAD}$, but they can still offer an opportunity to investigate the early pathological disease mechanisms.

The earliest studies on animal models were approached by Magnetic Resonance Spectroscopy (MRS) and investigated neurochemical profiles in cerebrum samples. Examination on cerebral cortex (Dedeoglu et al., 2004), cortex and hippocampus (Marjanska et al., 2005), and frontal cortex (von Kienlin et al., 2005) showed a decrease in the levels of $\mathrm{N}$ acetylaspartate (NAA) and glutamate in the brains where amyloid toxicity was widespread. In addition, these metabolites have been found to correlate (negatively) with brain amyloid burden (von Kienlin et al., 2005). Studies utilizing different analytical platforms have also reported decreased NAA and glutamate levels; these include studies utilizing NMR on APP transgenic mouse hippocampus, cortex, frontal cortex, midbrain and cerebellum (Salek et al., 2010), and GCMS metabolomics on PS1 transgenic hippocampus (Trushina et al., 2012). Glutamate is a primary excitatory neurotransmitter and its decreased levels may reflect a loss of glutamatergic neurons or decreased glutamate activity (Lin et al., 2003). Biological function of NAA in the brain is not well understood, but it is commonly regarded as a marker of neuronal density and integrity (Schuff et al., 1997). A diagnostic test based on the decreased levels of NAA and glutamate in APP $\times$ PS2 mice brains was able to classify 'AD like' mice from normal mice with $92 \%$ sensitivity and $82 \%$ specificity (von Kienlin et al., 2005). In addition to decreased levels of NAA and glutamate, these studies have also reported myo-inositol (m-In) content elevated in APP and PS1 mouse cerebrums (Marjanska et al., 2005; Woo et al., 2010; Forster et al., 2012). M-In is predominantly expressed in glial cells compared to neurons; its levels are considered to be indicative of osmotic stress and astroglosis (Castillo et al., 2000). However, other mouse model studies have shown contradicting results (Salek et al., 2010; Trushina et al., 2012).

Assays using NMR on plasma and liver samples from APP $\times$ PS1 transgenic mice showed significant changes in levels of lipids, nucleotides and energy-related metabolites, suggesting occurrence of oxidative stress and impaired energy metabolism (Wu et al., 2016). The impaired energy metabolism was also visible when serum samples were subjected to NMR, glucose, citrate, 3-hydroxybutyrate, pyruvate were found to be decreased (Liang et al., 2008). Moreover, analysis on urine samples from APP mice revealed significant metabolic alterations (increased levels of 3-hydroxykynurenine, homogentisate and allantoin) indicative of oxidative stress (Fukuhara et al., 2013).

While NMR or MRS platforms are ideal for detecting highly abundant metabolites (particularly those involved in energy metabolism), MS based metabolomics allows to look at a wider range of the metabolome network. Direct MS analysis on APP transgenic mouse cortex and cerebellum showed lower sulfatide levels (Cheng et al., 2010), while perturbations in homeostasis of lipids, energy management, and metabolism of amino acids and nucleotides were visible on APPxPS1 hippocampus and cortex (Gonzalez-Dominguez et al., 2015h). Employing ultra high resolution MS instruments, Lin et al., (2013) were able to observe over-production of eicosanoids indicating neuroinflammation on hippocampal tissues (Lin et al., 2013), and enhanced biosynthesis of amino acid and amino acid derivatives in cerebellum (Lin et al., 2014). Blood metabolomics using MS has identified numerous disturbed pathways in serum samples from APPxPS1 mouse, including perturbed phospholipid homeostasis, energy-related failures, hyperammonemia, inflammation (increased eicosanoids), among others (Gonzalez-Dominguez et al., 2015c). Peripheral organs from APPxPS1 Tg mouse models have included liver, kidneys, spleen and thymus (GonzalezDominguez et al., 2015e). The findings demonstrated significant impairments in energy metabolism, lipid homeostasis, oxidative stress and amino acids metabolism. These findings were largely consistent with those found from $\mathrm{Tg}$ mouse brain tissue samples (Lin et al., 2014; Lin et al., 2013; Gonzalez-Dominguez et al., 2015h). These findings highlighted the systemic nature of $\mathrm{AD}$ as metabolite dysregulation was seen in multi-organs, not just the brain.

Utilizing MS coupled with chromatography allows detection of a broader network of metabolic pathways when compared to NMR or direct MS approaches. Whole brain metabolic profiles from APPxPS1 revealed perturbations related to amino acid metabolism and steroid biosynthesis $(\mathrm{Hu}$ et al., 2012). Impairment in sterol metabolic pathway has also been visible in terms of increased cholesterol and cholesterol ester levels on whole brain (Sharman et al., 2010; Tajima et al., 2013) and hippocampal tissues (Wang HL et al., 2014). Lipid analysis on APPxPS1 Tg mouse whole brain samples showed elevated levels of lysophophatidylcholines (LysoPC), free fatty acids, monoacylglycerols and phosphatidic acids (Piro et al., 2012). The study was also able to identify significant perturbations in brain eicosanoids (Piro et al., 2012), in line with another study (Lin et al., 2013). Further inactivation of monoacylglycerol lipase has been found to reverse the perturbated metabolism of eicosanoids and reduce neuroinflammation (Piro et al., 2012). LC-MS techniques have also been applied for analysing hydrophilic metabolites in urine samples from CRND8 transgenic mice. Significant changes were observed in urinary levels of multiple families of metabolites; these included amino acids, fatty acids and neurotransmitter conjugates (Peng et al., 2014; Tang et al., 2016). Altered levels of these metabolites have been identified in brain and blood samples as well (Dedeoglu et al., 2004; Liang et al., 2008; Salek et al., 2010; Lin et al., 2013), suggesting whole body response to AD.

González-Domínguez et al. has employed a combination of GC-/LC- MS platforms and using the APPxPS1 mouse model has shown numerous alterations in the homeostasis of lipids, amino acids, nucleotides, energy-related metabolites and some other compounds in the whole organism, including in serum (Gonzalez-Dominguez et al., 2015d), liver and kidney (Gonzalez-Dominguez et al., 2015f), spleen and thymus (Gonzalez-Dominguez et al., 2015i), and various regions of the brain (Gonzalez-Dominguez et al., 2014d). Many of these impairments could also be detected in APP mouse hippocampus when the same methodology was applied (Trushina et al., 2012).

Summary of metabolomics studies conducted in animal models of AD can be seen in Table 2 . 
Table 2. Summary of metabolomics studies conducted in animal models of AD.

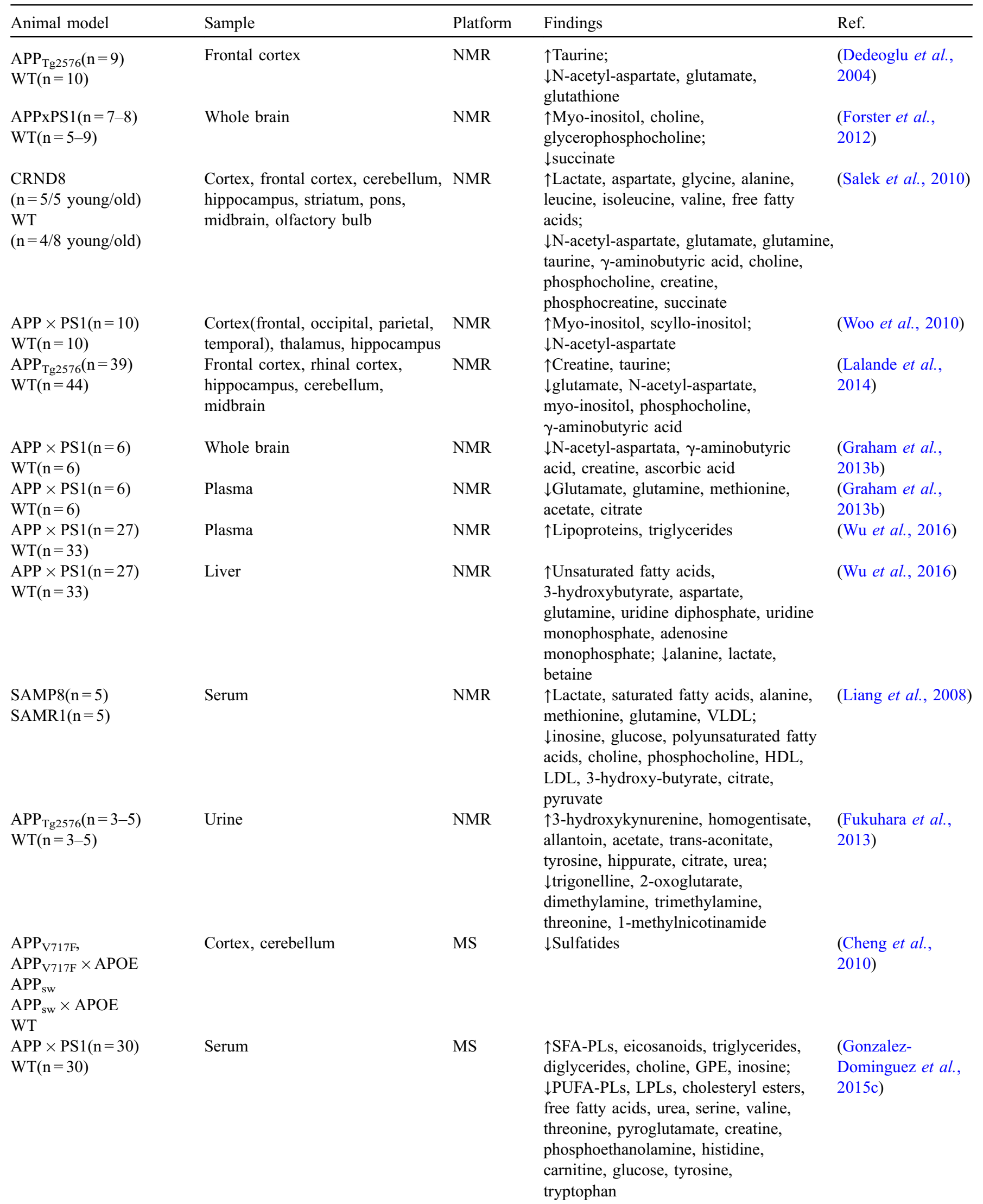

$\mathrm{WT}(\mathrm{n}=10)$

$\operatorname{APP}_{\operatorname{Tg} 2576}(\mathrm{n}=39)$

$\mathrm{WT}(\mathrm{n}=44)$

$\mathrm{APP} \times \operatorname{PS} 1(\mathrm{n}=6)$

APP $\times \operatorname{PS} 1(n=27)$

$\mathrm{WT}(\mathrm{n}=33)$

APP $\times$ PS1 $(n=27)$

$\mathrm{WT}(\mathrm{n}=33)$

$\operatorname{SAMP} 8(\mathrm{n}=5)$

$\operatorname{SAMR} 1(\mathrm{n}=5)$

$\operatorname{APP}_{\operatorname{Tg} 2576}(\mathrm{n}=3-5)$

Urine

pyruvate

allantoin, acetate, trans-aconitate,

dimethylamine, trimethylamine,

threonine, 1-methylnicotinamide

$\mathrm{APP}_{\mathrm{V} 717 \mathrm{~F}} \times \mathrm{APOE}$

$\mathrm{APP}_{\mathrm{sw}}$

$\mathrm{APP}_{\mathrm{sw}} \times \mathrm{APOE}$

APP $\times \operatorname{PS} 1(n=30)$

$\mathrm{WT}(\mathrm{n}=30)$ diglycerides, choline, GPE, inosine;

$\downarrow$ PUFA-PLs, LPLs, cholesteryl esters, phosphoethanolamine, histidine, tryptophan 
Table 2. (continued).

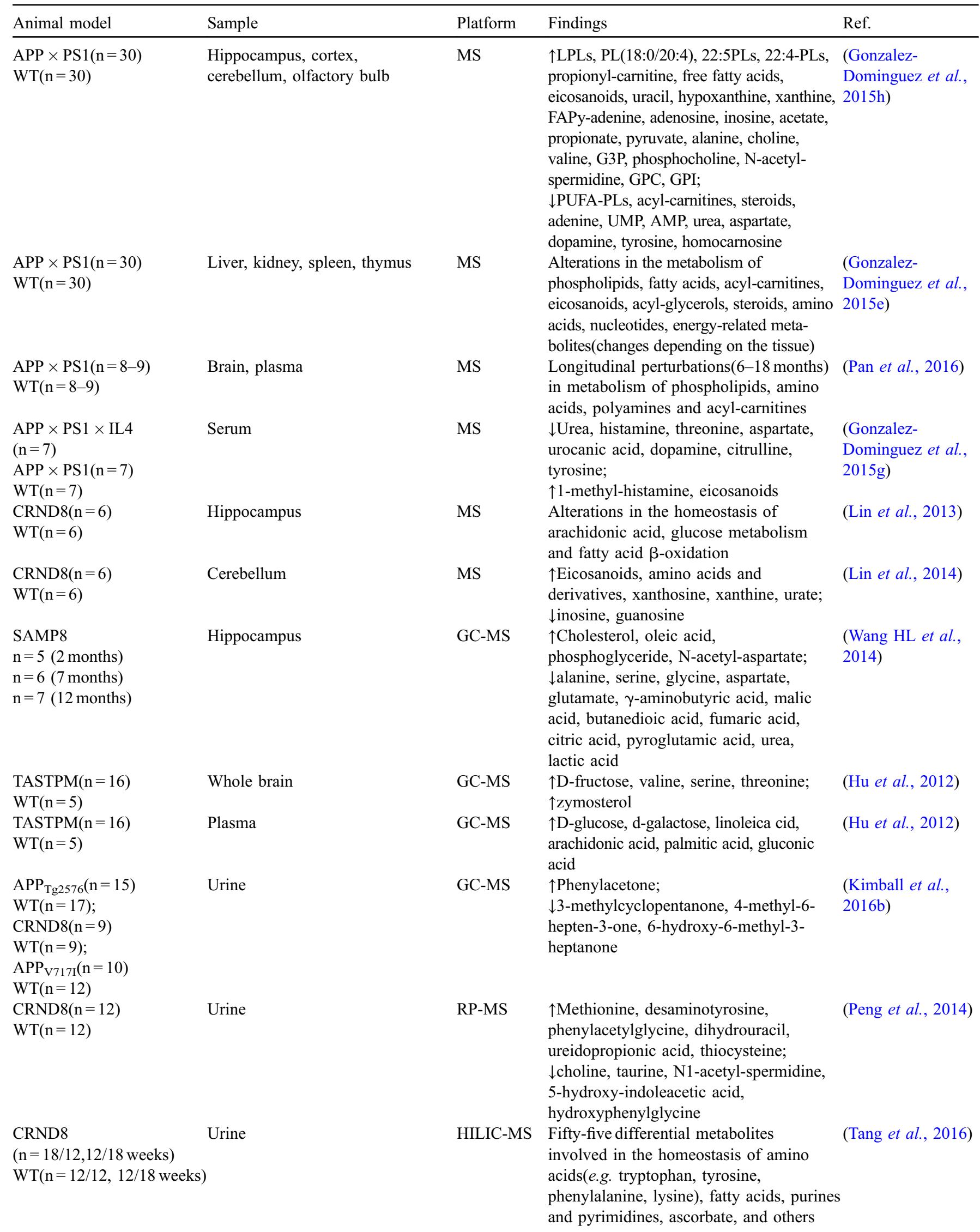


Table 2. (continued).

\begin{tabular}{|c|c|c|c|c|}
\hline Animal model & Sample & Platform & Findings & Ref. \\
\hline $\begin{array}{l}\text { APP } \times \operatorname{PS} 1(n=30) \\
W T(n=30)\end{array}$ & $\begin{array}{l}\text { Hippocampus, cortex, striatum, } \\
\text { cerebellum, olfactory bulb }\end{array}$ & $\begin{array}{l}\text { RP-MS/ } \\
\text { GC-MS }\end{array}$ & $\begin{array}{l}\text { Alterations in the metabolism of } \\
\text { phospholipids, sphingolipids, energy- } \\
\text { related metabolites, amino acids and } \\
\text { nucleotides }\end{array}$ & $\begin{array}{l}\text { (Gonzalez- } \\
\text { Dominguez et al., } \\
\text { 2014d) }\end{array}$ \\
\hline $\begin{array}{l}\text { APP } \times \operatorname{PS} 1(n=30) \\
W T(n=30)\end{array}$ & Liver, kidney & $\begin{array}{l}\text { RP-MS/ } \\
\text { GC-MS }\end{array}$ & $\begin{array}{l}\text { Alterations in the metabolism of } \\
\text { phospholipids, sphingolipids, fatty acids, } \\
\text { acyl-carnitines, cholesterol and bile } \\
\text { acids, energy-related metabolites and } \\
\text { amino acids }\end{array}$ & $\begin{array}{l}\text { (Gonzalez- } \\
\text { Dominguez et al., } \\
\text { 2015f) }\end{array}$ \\
\hline $\begin{array}{l}\operatorname{APP}_{T 22576}(\mathrm{n}=3) \\
\operatorname{PS} 1(\mathrm{n}=3) \\
\operatorname{APP} \times \operatorname{PS} 1(\mathrm{n}=6) \\
\operatorname{WT}(\mathrm{n}=6)\end{array}$ & Hippocampus & $\begin{array}{l}\text { RP-MS/ } \\
\text { GC-MS }\end{array}$ & $\begin{array}{l}\text { Alterations in nucleotide, TCA cycle, } \\
\text { energy transfer, carbohydrate, } \\
\text { neurotransmitter and amino acid } \\
\text { metabolic pathways }\end{array}$ & $\begin{array}{l}\text { (Trushina et al., } \\
\text { 2012) }\end{array}$ \\
\hline
\end{tabular}

\subsection{Metabolomics in AD patients}

While animal models represent at best familial AD, not sporadic forms such as LOAD which have multifactorial origins, human studies can also be challenging because of multifactorial issues, such as disease severity and comorbidities, together with the difficulty of organizing big cohorts to correct appropriately for this variation.

\subsubsection{Brain}

The earliest metabolomics studies on AD focused on postmortem brain samples, utilizing MRS as an analytical platform. In vitro analyses were performed in order to quantify the content of some important neurochemicals in different brain regions. These studies commonly identified reduced levels of N-acetyl-asparate, glutamate and glutamine, together with increased myo-inositol content (Klunk et al., 1992; Miller et al., 1993; Mohanakrishnan et al., 1995; Shonk et al., 1995; Mohanakrishnan et al., 1997). Shonk et al., (1995) evaluated these metabolites as putative neuronal markers, and found that the ratio of myo-inositol and $\mathrm{N}$-acetyl-aspartate was able to distinguish AD from normality with $83 \%$ sensitivity and $98 \%$ specificity. It is interesting to note that these changes were also identified in the brains of adult AD-like mouse in the presence of amyloid burden (Dedeoglu et al., 2004; Marjanska et al., 2005; von Kienlin et al., 2005; Salek et al., 2010) as well as in the brains of young APPxPS1 Tg mouse in the absence of amyloid plaques (Wengenack et al., 2000; Marjanska et al., 2005).

More recently, non-targeted approaches utilizing NMR technique have been employed. Graham et al., (2014) were able to identify increased alanine and taurine levels in the neocortex region of $\mathrm{AD}$ brains; ratio of these two metabolites was found to discriminate $\mathrm{AD}$ from controls with Receiver
Operation Characteristic (ROC) area under curve (AUC) value of $76 \%$. Further when cortical profiles between $\mathrm{AD}$ and amyotrophic lateral sclerosis (ALS) were compared using the same methodology, alanine, glutamate and glutamine levels were found to be increased in $\mathrm{AD}$, highlighting these abnormalities to be AD specific (Botosoa et al., 2012).

Numerous studies have applied DIMS due to its highthroughput capability. In 2001, Han et al., (2001) reported a decrease in plasmalogen content in cerebellar white matter at a very mild stage of ADs, a trend which was also later seen in AD grey matter (Wood et al., 2015). In the following year, Han et al., (2002) attempted to reproduce the finding of decreased plasmalogen levels in AD brain, but was unable to observe the change at a significant level. Instead the group observed depletion in sulfatide levels in white matter and grey matter regions (Han et al., 2002), a finding that was later seen in a mouse model study (Cheng et al., 2010). Sulfatide is known to mediate diverse biological processes including myelination, signal transduction, neuronal plasticity and cell morphogenesis (Vos et al., 1994; Merrill et al., 1997), suggesting sulfatide loss may lead to neuronal dysfunction and AD pathogenesis (Han et al., 2002). Interestingly, depletion of brain sulfatide level was also observed in pre-clinical AD (Cheng et al., 2010) and mild AD (Wood et al., 2015), suggesting that sulfatide deficiency is possibly among the early events of $\mathrm{AD}$ development.

More hydrophilic brain metabolites have also been found to be associated to AD pathology. Recently, Xu et al., (2016) employed GC-MS to compare profiles of $9 \mathrm{AD}$ brains to 9 control brains, in 9 different brain regions. The group detected 55 metabolites differentiating the two cohorts; these 55 metabolites were mainly amino acid and nucleoside, highlighting presence of widespread metabolic perturbations in AD brain (Xu et al., 2016). Utilizing the same analytical technique on 43 brain samples, Snowden et al., (2017) showed 
dysregulation in unsaturated fatty acid metabolism in the brains for patients with varying degrees of AD pathology.

LC-MS has also been employed to compare metabolic profiles of $\mathrm{AD}$ brains to those of control brains, a recent study has found a significant increases in the levels of spermine and spermidine were identified in AD brains, suggesting involvement of an abnormal brain expression of the polyamine pathway in AD pathogenesis (Inoue et al., 2013). More recently, a targeted metabolomics approach has been utilized where glucose level was measured from 14 control, $14 \mathrm{AD}$ and 15 asymptomatic AD brains (An et al., 2017). The study showed higher brain glucose levels associating with AD pathology and the expression of $\mathrm{AD}$ symptoms, further highlighting glucose hypometaolism in AD brain (An et al., 2017).

\subsubsection{CSF}

CSF is an ideal matrix because of its direct contact with the extracellular space in the brain, thus directly reflecting the brain's metabolic production. Kaddurah-Daouk et al., (2011) examined levels of metabolites involved in key neurotransmitter pathways and oxidative stress using 30 post-mortem ventricular CSF samples (15 AD vs $15 \mathrm{CN}$ ). For this purpose, a metabolic platform based on LCECA with pentane sulfonic acid as ion-paring agent was employed. The study observed depletion of norephinephrine, methionine, $\alpha$-tocopherol and 3 methoxytyramine levels and increased levels of 5-hydroxytryptophan in AD (Kaddurah-Daouk et al., 2011). However, it is important to note that this study utilized post-mortem CSF samples (Kaddurah-Daouk et al., 2011). Along with brain samples discussed in the earlier section, post-mortem samples generally imply the severe-phase of $\mathrm{AD}$ at the time of collection. Additionally, metabolite levels in post-mortem tissue/biofluid samples may be impacted by the death process (as well as post-mortem intervals) (Trushina and Mielke, 2014).

NMR-based metabolomics to CSF samples have demonstrated great utility in differentiating AD from CN (Jukarainen et al., 2008; Kork et al., 2009; Laakso et al., 2015). One of these studies quantified 31 metabolites from $76 \mathrm{AD} v s 45 \mathrm{CN}$ CSF samples and found that these metabolites were able to classify the samples correctly with an accuracy of $85.5 \%$ (Laakso et al., 2015). LCECA has also been employed; Kaddurah-Daouk et al., (2013) looked into metabolic profiles of $50 \mathrm{AD}, 36 \mathrm{MCI}$ and $15 \mathrm{CNCSF}$ samples and was able to reveal elevated levels of methionine and 5-hydroxyindoleacetic acid in AD and MCI compared to $\mathrm{CN}$ samples. These metabolites were also found to be related to CSF $A \beta_{42}$, indicating the perturbations in pathways involving methionine and 5-hydroxyindoleacetic acid could be associated with amyloidgenic pathway (Kaddurah-Daouk et al., 2013).

Multi-platforms based on the combination of complementary chromatographic science prior to MS detection have also been employed (Czech et al., 2012; Ibanez et al., 2013; Trushina et al., 2013a). Utilizing RP and HILIC, Trushina et al., (2013a) analysed 15 AD, $15 \mathrm{MCI}$ and $15 \mathrm{CNCSF}$ samples, and found approximately $30 \%$ of the metabolic pathways altered in MCI compared to $\mathrm{CN}$, and $60 \%$ in $\mathrm{AD}$ compared to $\mathrm{CN}$. This finding showed that the number of affected pathways increases with disease severity.
Another multiplatform available for CSF metabolic profiling is the combination of GC-MS and LC-MS methodology. Using this technique, Czech et al., (2002) were able to establish differences in catercholamines and steroids in the CSF samples from $51 \mathrm{CN}, 53$ mild $\mathrm{AD}$ and 26 moderate AD participants. The group also found increased cortisol levels associating with the AD progression, while combination of cysteine and various amino acids provided predictive models with sensitivity and specificity above 80\% (Czech et al., 2012).

A recent study employed CE-MS to monitor perturbations in the polar metabolome associated with $\mathrm{AD}$ progression by analysing CSF from subjects with different cognitive status, AD, MCI that progressed to $\mathrm{AD}$ within 2 years, MCI that remained stable after 2 years, and subjective cognitive impairment (Ibanez et al., 2012). Initially, ten metabolites including choline, valine, arginine, suberylglycerin, carnitine, creatine, serine and histidine were identified from 73 samples with classification accuracy of $90.1 \%$ for the four groups. The group then tested the classification model into 12 test samples, initially blinded to diagnosis, and $83 \%$ of the samples were correctly classified, indicating these polar CSF metabolites could potentially be utilized as a diagnostic tool (Ibanez et al., 2012). The same group employed the combination of orthogonal RP-MS and HILIC-MS on the same sample cohorts (Ibanez et al., 2013). From statistical modelling, 17 metabolites were identified showing strong association with cognitive status related to AD, and classification model based on these 17 metabolites was able to predict the development of AD with an accuracy of $98.7 \%$, and sensitivity and specificity values above $95 \%$. The model included altered level of histidine (Ibanez et al., 2013), which was also present their previous work (Ibanez et al., 2012).

\subsubsection{Blood}

Blood biomarkers would be ideal for their implementation in the clinical practice. CSF metabolites may be more reflective of brain changes but CSF collection is invasive, making it unsuitable for screening purposes. As a result, it is no surprise that most of the metabolic profiling studies have focused on blood-based biomarkers.

González-Domínguez et al., (2014b, 2014c, 2014e, 2015a) studied serum lipid profiles by utilizing various lipid extraction and DI-MS, each technique focusing on different classes of blood metabolites. The group has been able to detect abnormal overproduction of several molecular species:

- glycerides indicating membrane breakdown;

- prostaglandins, imidazole and histidine indicating oxidative stress;

- glutamine, glutamate and dopamine indicating impaired neurotransmission systems.

Other groups also employed DIMS for profiling of blood metabolites and found altered levels of long-chain sphingomyelines and ceramides (Han X et al., 2011), plasmalogen and diglycerdies (Wood et al., 2016), and phospholipids (Klavins et al., 2015).

Focusing on lipid profiles, Sato et al., (2012) was able to find a considerable reduction in circulating demosterol levels in AD plasma, both in untargeted and targeted analyses. Other plasma lipids classes reported to have close relationships with AD included bile acids (Greenberg et al., 2009), LysoPCs and 
Table 3. Summary of metabolomics studies conducted in AD human samples.

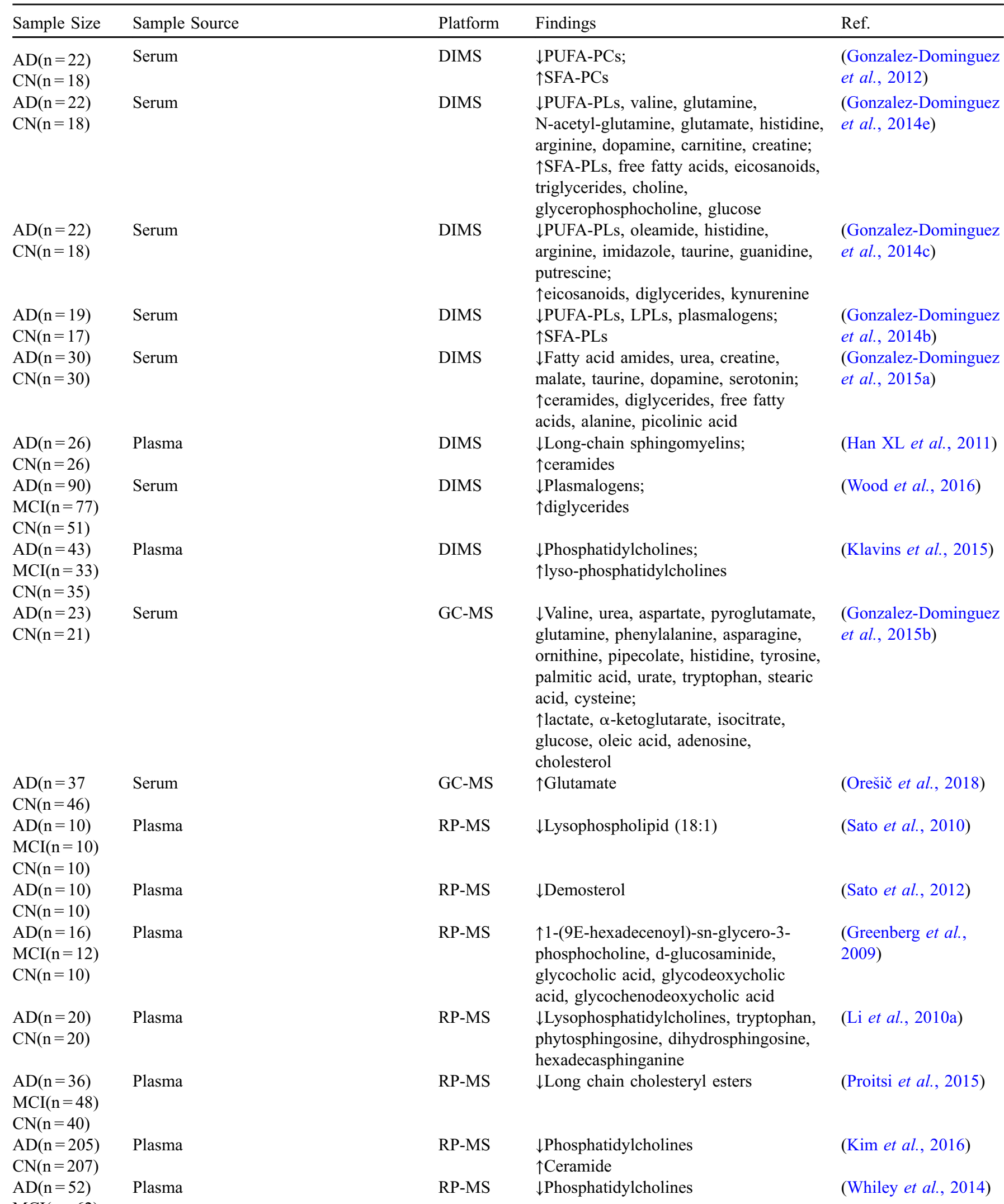

$\operatorname{MCI}(\mathrm{n}=62)$

$\mathrm{CN}(\mathrm{n}=59)$ 
Table 3. (continued).

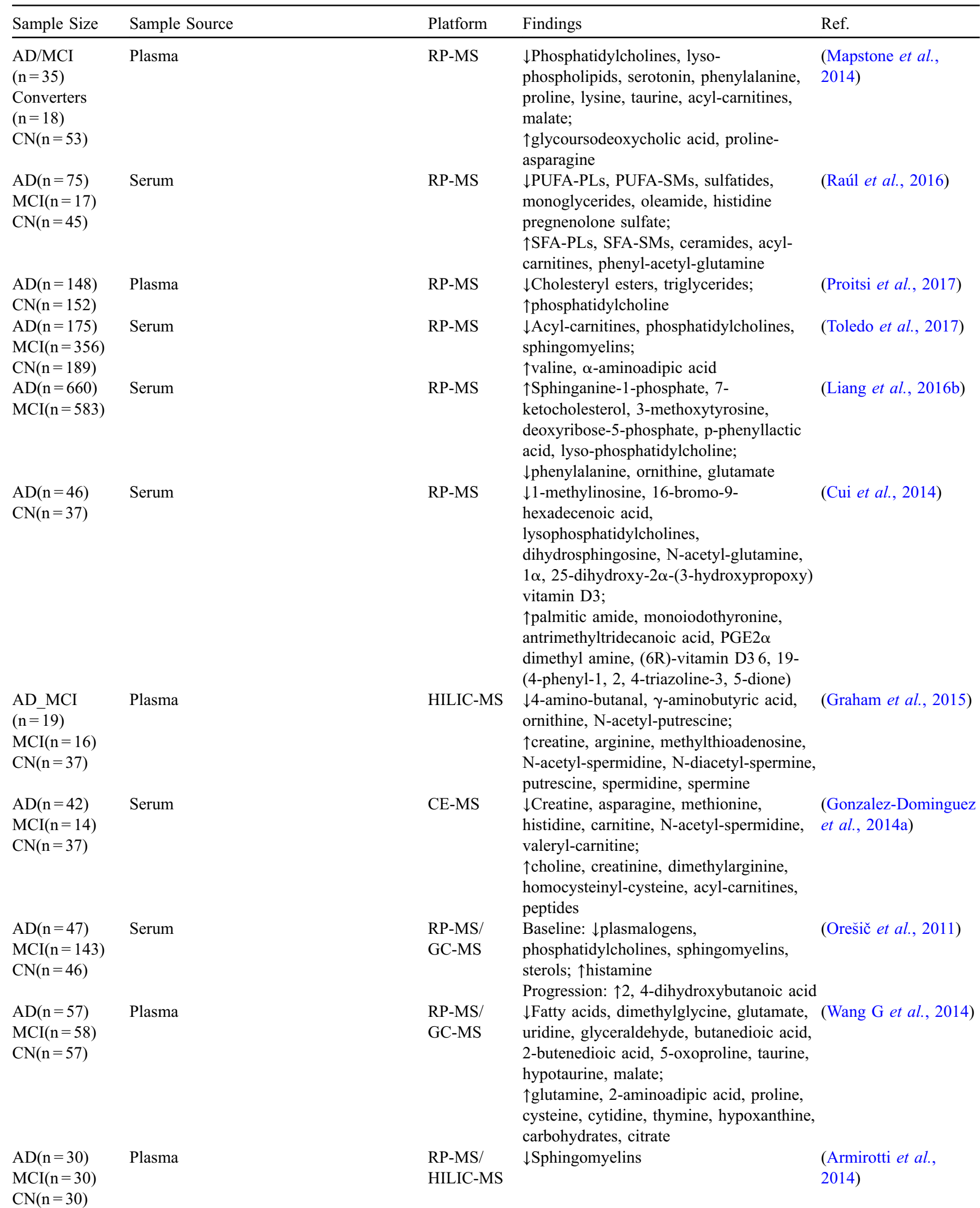


Table 3. (continued).

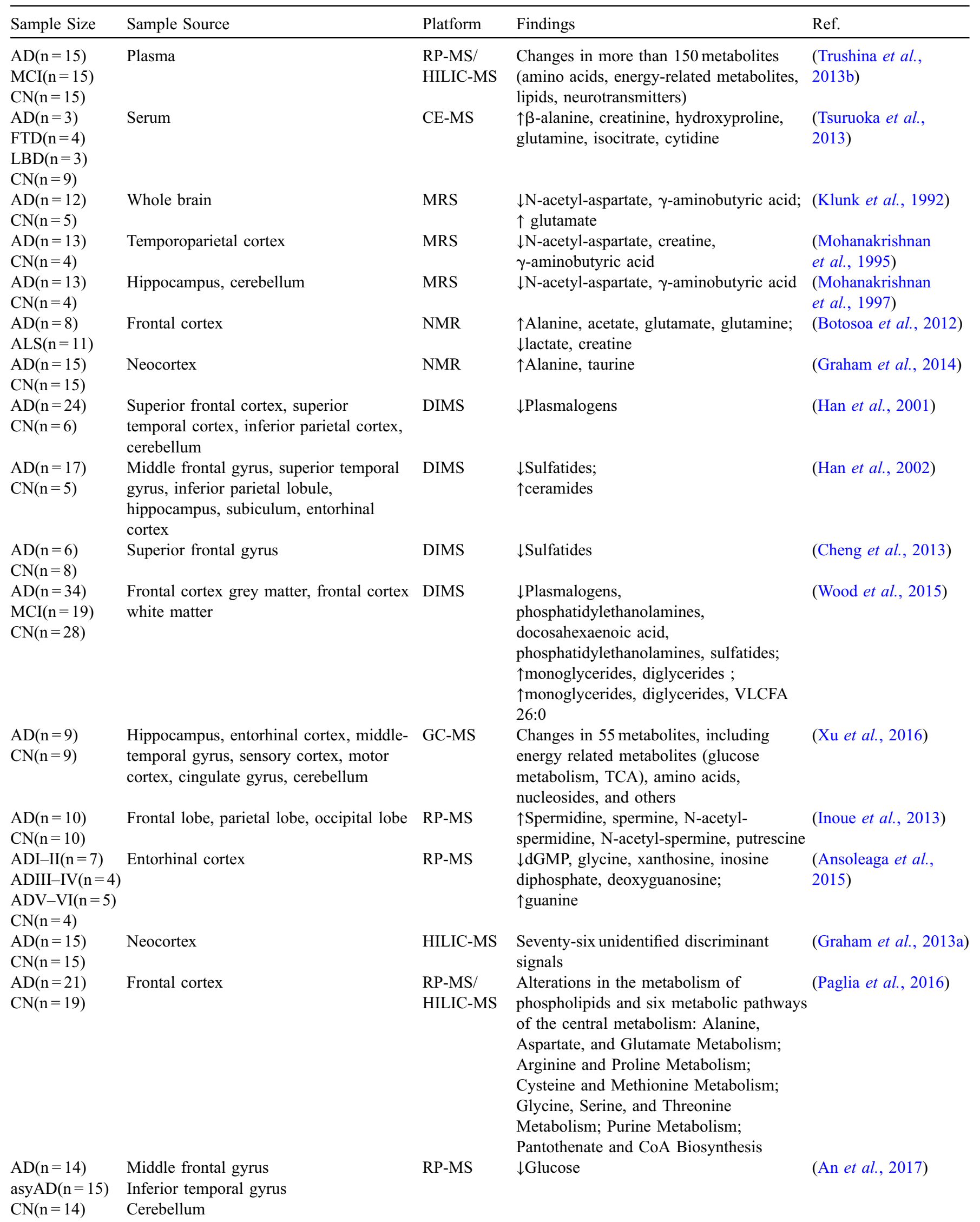


Table 3. (continued).

\begin{tabular}{ll}
\hline Sample Size & Sample Source \\
\hline $\operatorname{AD}(n=14)$ & Middle frontal gyrus \\
asyAD $(n=15)$ & Inferior temporal Gyru \\
$\mathrm{CN}(n=14)$ & Cerebellum
\end{tabular}

$\mathrm{AD}(\mathrm{n}=15) \quad$ Post-mortem CSF

$\mathrm{CN}(\mathrm{n}=15)$

\begin{tabular}{|c|c|}
\hline \multicolumn{2}{|l|}{$\mathrm{AD}(\mathrm{n}=34)$} \\
\hline $\operatorname{MCI}(n=19)$ & \\
\hline $\mathrm{CN}(\mathrm{n}=28)$ & \\
\hline $\mathrm{AD}(\mathrm{n}=20)$ & CSF \\
\hline $\mathrm{CN}(\mathrm{n}=27)$ & \\
\hline $\mathrm{AD}(\mathrm{n}=10)$ & CSF \\
\hline $\mathrm{CN}(\mathrm{n}=34)$ & \\
\hline $\mathrm{AD}(\mathrm{n}=76)$ & $\mathrm{CSI}$ \\
\hline early_AD & \\
\hline$(n=26)$ & \\
\hline $\operatorname{MCI}(\mathrm{n}=33)$ & \\
\hline $\mathrm{CN}(\mathrm{n}=45)$ & \\
\hline $\mathrm{AD}(\mathrm{n}=50)$ & CSF \\
\hline $\mathrm{CN}(\mathrm{n}=50)$ & \\
\hline $\mathrm{AD}(\mathrm{n}=17)$ & CSF \\
\hline $\mathrm{CN}(\mathrm{n}=17)$ & \\
\hline $\mathrm{AD}(\mathrm{n}=40)$ & CSF \\
\hline $\operatorname{MCI}(n=36)$ & \\
\hline $\mathrm{CN}(\mathrm{n}=38)$ & \\
\hline $\mathrm{AD}(\mathrm{n}=23)$ & CSF \\
\hline $\mathrm{AD} \operatorname{MCI}(\mathrm{n}=9)$ & \\
\hline $\operatorname{sMC} \mathrm{C}(\mathrm{n}=22)$ & \\
\hline $\mathrm{CN}(\mathrm{n}=19)$ & \\
\hline $\mathrm{AD}(\mathrm{n}=79)$ & CSF \\
\hline $\mathrm{CN}(\mathrm{n}=51)$ & \\
\hline $\mathrm{AD}(\mathrm{n}=40)$ & $\mathrm{CSF}$ \\
\hline $\mathrm{CN}(\mathrm{n}=38)$ & \\
\hline $\mathrm{AD}(\mathrm{n}=21)$ & $\mathrm{CS}$ \\
\hline $\operatorname{cMCI}(\mathrm{n}=12)$ & \\
\hline $\operatorname{sMCI}(\mathrm{n}=21)$ & \\
\hline $\mathrm{CN}(\mathrm{n}=21)$ & \\
\hline
\end{tabular}

LCECA

MS

NMR Specific resonances in AD (unidentified)

NMR $\quad \uparrow$ Creatinine

NMR

DIMS

RP-MS Fifty-three unidentified discriminant signals

RP-MS $\quad \uparrow$ Methionine, 5-hydroxyindoleacetic acid, vanillylmandelic acid, xanthosine, glutathione, hypoxanthine

CE-MS $\downarrow$ Arginine, suberylglycine, carnitine, histidine;

$\uparrow$ choline, valine, tripeptide,

dimethylarginine, creatine, serine

RP-MS/ $\downarrow$ Uridine;

GC-MS $\quad \uparrow$ cysteine, tyrosine, phenylalanine, methionine, serine, pyruvate, taurine, creatinine, cortisol, dopamine

RP-MS/ Two unidentified discriminant signals

GC-MS

RP-MS/ HILIC-MS
Changes in levels of uracil, xanthine, uridine, tyrosyl-serine, methylsalsolinol, nonanoylglycine, dopamine-quinone, caproic acid, vanylglycol, histidine, pipecolic acid, hydroxyphophinylpiruvate, creatinine, taurine, C16sphingosine-1-phosphate, tryptophan, $5^{\prime}$-methylthioadenosine
Ref.

(Snowden et al., 2017)

(Kaddurah-Daouk et al., 2011)

(Wood et al., 2015)

(Kork et al., 2009)

(Jukarainen et al., 2008)

(Laakso et al., 2015)

(Koal et al., 2015)

(Myint et al., 2009)

(Kaddurah-Daouk et al., 2013)

(Ibanez et al., 2012)

(Czech et al., 2012)

(Motsinger-Reif et al., 2013)

(Ibanez et al., 2013) 
Table 3. (continued).

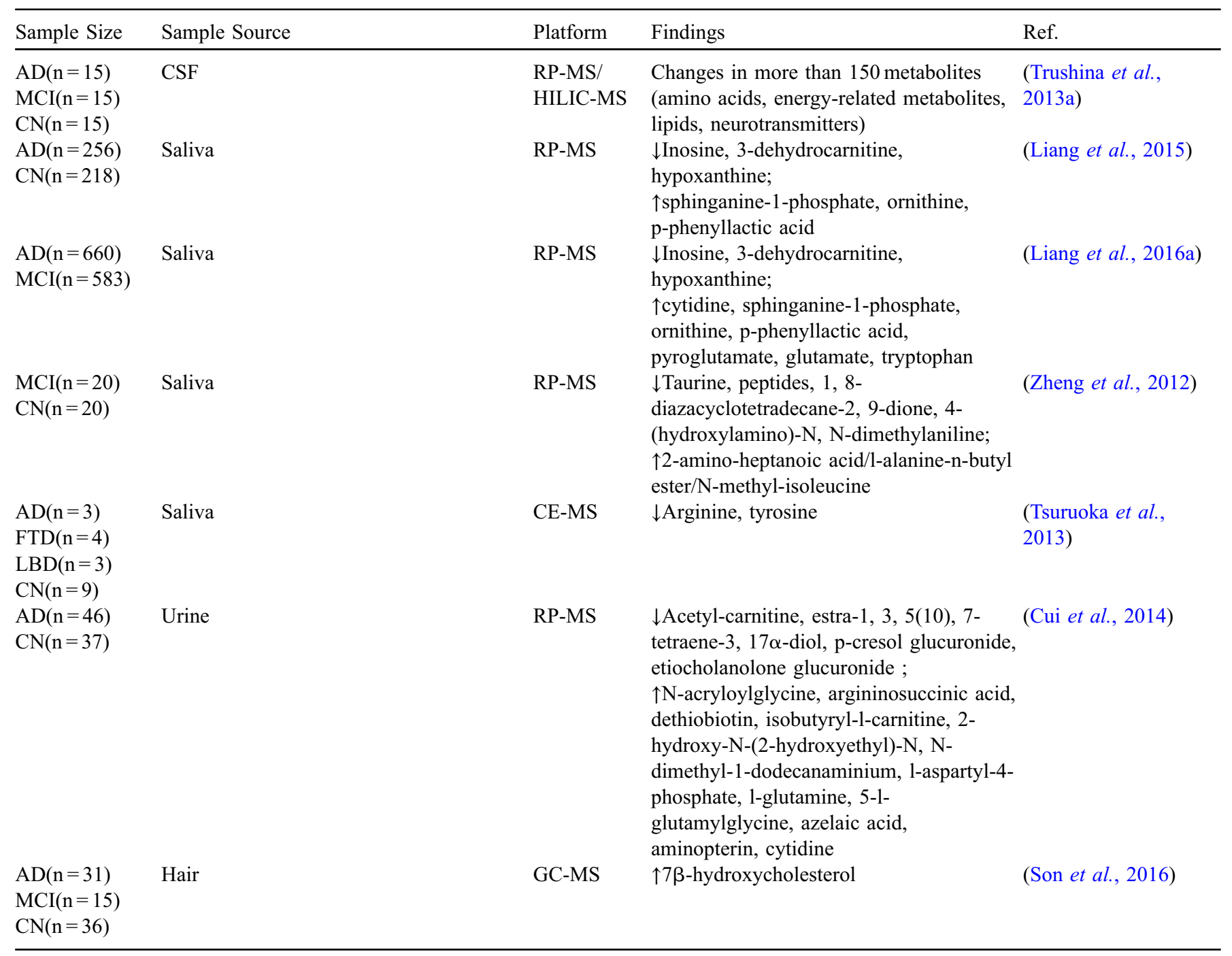

phytosphingosine (sphingolipid precursors) (Li et al., 2010b), among others (Mapstone et al., 2014). Utilizing in-vial dual extraction protocol (Whiley et al., 2012; Godzien et al., 2013), abnormal levels of long chain cholesteryl esters/triglycerides (Proitsi et al., 2015; Proitsi et al., 2017) and omega-3 containing PC molecules (Whiley et al., 2014; Kim et al., 2016) have been shown in two separate study cohorts. Additionally, increased plasma levels of phosphorylethanolamine (PE) and PC species have been found to associate with brain amyloid burden (Voyle et al., 2016).

Focusing on more hydrophilic blood metabolites, a study involving $75 \mathrm{AD}, 17 \mathrm{MCI}$ and $45 \mathrm{CN}$ serum samples revealed accumulation of acylcarnitine in relation to mitochondrial dysfunction, and lower levels of oleamide and monoglycerides caused by impaired endocannabionoid system (GonzalezDominguez et al., 2016). A study involving much bigger cohorts of $660 \mathrm{AD}$ and $583 \mathrm{MCI}$ serum samples found increased levels of sphinganine-1-phosphate and 7-ketocheolsterol; the combination of these metabolites predicting AD conversion with accuracy value of 95\% (Liang et al., 2016b).
These two metabolites have also been found to be strong AD discriminators from $\mathrm{MCI}$ and $\mathrm{CN}$ in saliva samples (Liang et al., 2015, 2016a).

HILIC-MS has shown disturbance in 22 biochemical pathways, including homeostasis of polyamines and arginine metabolism (Graham et al., 2015), while CE-MS revealed the presence of oxidative stress and defects in energy metabolism (Tsuruoka et al., 2013; Gonzalez-Dominguez et al., 2014a). Utilizing a RP-MS/HILIC-MS multi-platform, Trushina et al., (2013b) identified 154 metabolites with significant changes in AD vs CN subjects (Trushina et al., 2013b) while Armirotti et al., (2014) has employed RP-MS/ HILIC-MS multi-platform to find abnormally high levels of sphingomyelins in AD blood. Wang G et al., (2014) looked at profiles of $57 \mathrm{AD}, 58 \mathrm{MCI}$ and 57CN plasma samples in 2014 and identified a panel of 6 metabolites discriminating AD from $\mathrm{CN}$ with ROC AUC of 1, and a panel of 5 metabolites discriminating MCI from CN with ROC AUC of 0.998. In a prospective study with aim to determine serum metabolomic profiles associating with progression and diagnosis of 
AD, Orešič et al., (2011) has utilized GC-MS/RP-MS to compare blood metabolic profiles of stable MCIs and converting MCIs. A panel of 3 metabolites (lower levels of one PC, one carboxylic acid and 2-4-dihydroxybutanoic acid molecules) was identified to be associated with progressive $\mathrm{MCI}$; its AD conversion predictive value (ROC AUC) was 0.77 (Orešič et al., 2011).

Most recently, Toledo et al. employed a targeted approach and quantified 187 serum metabolites from $199 \mathrm{CN}, 356 \mathrm{MCI}$ and $175 \mathrm{AD}$ participants. (Toledo et al., 2017). The study was able to reveal abnormal changes in sphingomyleins and $\mathrm{PC}$ levels related to early stages of $\mathrm{AD}$, as well as abnormal changes in acylcarnitines and several amines levels related to later symptomatic stages of $\mathrm{AD}$. The group hypothesized that dysregulation in lipid metabolism during early stages of AD leads to breakdown in lipid membranes which consequently results in disruption in energy metabolism seen during later stages of AD. In another study where targeted approach was employed, a comparison between $38 \mathrm{AD}$ and 46 control serum metabolic profiles showed an increase glutamate levels in AD (Orešič et al., 2018).

\subsubsection{Saliva, urine and hair}

Saliva, urine and hair metabolites have been studied due to their ease-to-collect. Tsuruoka et al., (2013) analysed saliva metabolic profiles to complement serum metabolic profiles by employing CE-MS. Abnormal levels of arginine and tyrosine in $\mathrm{AD}$ saliva samples were found when compared to $\mathrm{CN}$ samples as well as FTD and LBD samples, highlighting the abnormal levels of arginine and tyrosine as specific to AD (Tsuruoka et al., 2013). In a study involving urine samples, Cui et al., (2014) employed RP-MS and discovered impaired metabolic pathways involving L-glutamine and 5-L-glutamylglycine in AD. The study then utilized these two metabolites to test their AD predictive abilities, and the corresponding ROC AUC values were 0.709 and 0.700 respectively (Cui et al., 2014).

In more recent years, sterol profiles of hair have been exploited as a possible source of AD markers due to hair being able to reflect biochemical stress at the local or at systemic levels (Slominski and Wortsman, 2000; Slominski et al., 2012). Son et al., (2016) analysed $31 \mathrm{AD}, 15 \mathrm{MCI}$ and $36 \mathrm{CN}$ hair samples by employing GC-MS and discovered an increased amount of $7 \beta$-hydroxycholesterol as a possible AD predictive biomarker. Ratio of $7 \beta$-hydroxycholesterol to cholesterol was found to be able to discriminate MCI vs CN and $\mathrm{AD}$ vs CN with ROC AUC values of 0.750 and 0.729 respectively (Son et al., 2016).

Summary of metabolomics studies conducted on samples from AD participants can be seen in Table 3.

\section{Conclusion}

Overall, an extensive number of studies have applied metabolomics in order to identify:

- perturbations in metabolic pathways that reflect changes associated with AD pathology;

- a panel of metabolites which would potentially be used as an $\mathrm{AD}$ diagnostic tool.
Taking together the findings, it seems clear that multiple metabolic alterations could be occurring during progression to AD. These include lipids, metabolites involved in neurotransmitter systems and energy metabolism.

Acknowledgements. Cristina Legido-Quigley is partially supported from the Innovative Medicines Initiative Joint Undertaking under EMIF grant agreement No. 115372, resources of which are composed of financial contribution from the European Union's Seventh Framework Programme (FP7/2007-2013) and EFPIA companies' in-kind contribution.

\section{References}

Alzheimer's A. 2015. Alzheimer's disease facts and figures. Alzheimers Dement 11(3), 332-384. DOI: 10.1016/j. jalz.2015.02.003.

An Y, Varma VR, Varma S, et al. 2017. Evidence for brain glucose dysregulation in Alzheimer's disease. Alzheimers Dement. DOI: 10.1016/j.jalz.2017.09.011.

Ansoleaga B, Jove M, Schluter A, et al. 2015. Deregulation of purine metabolism in Alzheimer's disease. Neurobiol Aging 36(1): 6880. DOI: 10.1016/j.neurobiolaging.2014.08.004.

Armirotti A, Basit A, Realini N, et al. 2014. Sample preparation and orthogonal chromatography for broad polarity range plasma metabolomics: application to human subjects with neurodegenerative dementia. Anal Biochem 455: 48-54.

Arvanitakis Z, Schneider JA, Wilson RS, et al. 2008. Statins, incident Alzheimer disease, change in cognitive function, and neuropathology. Neurology 70(19): 1795-1802.

Atkinson AJ, Colburn WA, DeGruttola VG, et al. 2001. Biomarkers and surrogate endpoints: preferred definitions and conceptual framework. Clin Pharmacol Ther 69(3): 89-95.

Beckonert O, Keun HC, Ebbels TMD, et al. 2007. Metabolic profiling, metabolomic and metabonomic procedures for NMR spectroscopy of urine, plasma, serum and tissue extracts. Nat Protoc 2(11): 2692-2703.

Bertram L, Tanzi RE. 2008. Thirty years of Alzheimer's disease genetics: the implications of systematic meta-analyses. Nat Rev Neurosci 9(10): 768-778. DOI: 10.1038/nrn2494.

Bhattacharyya R, Kovacs DM. 2010. ACAT inhibition and amyloid beta reduction. Bba-Mol Cell Biol L 1801(8): 960-965.

Blennow K, Hampel H, Weiner M, Zetterberg H. 2010. Cerebrospinal fluid and plasma biomarkers in Alzheimer disease. Nat Rev Neurol 6(3): 131-144.

Botosoa EP, Zhu M, Marbeuf-Gueye C,et al. 2012. NMR metabolomic of frontal cortex extracts: first study comparing two neurodegenerative diseases, Alzheimer disease and amyotrophic lateral sclerosis. Irbm 33(5-6): 281-286.

Castillo M, Smith JK, Kwock L. 2000. Correlation of myo-inositol levels and grading of cerebral astrocytomas. Am J Neuroradiol 21 (9): 1645-1649.

Cheng H, Zhou YH, Holtzman DM, Han XL. 2010. Apolipoprotein E mediates sulfatide depletion in animal models of Alzheimer's disease. Neurobiol Aging 31(7): 1188-1196.

Cheng H, Wang M, Li JL, Cairns NJ, Han XL. 2013. Specific changes of sulfatide levels in individuals with pre-clinical Alzheimer's disease: an early event in disease pathogenesis. J Neurochem 127 (6): 733-738.

Corder EH, Saunders AM, Strittmatter WJ, et al. 1993. Gene dose of apolipoprotein E type 4 allele and the risk of Alzheimer's disease in late onset families. Science 261(5123): 921-923. 
Cui Y, Liu XQ, Wang MQ, et al. 2014. Lysophosphatidylcholine and amide as metabolites for detecting Alzheimer disease using ultrahigh-performance liquid chromatography-quadrupole timeof-flight mass spectrometry-based metabonomics. J Neuropath Exp Neur 73(10): 954-963.

Cummings J, Aisen PS, DuBois B, et al. 2016. Drug development in Alzheimer's disease: the path to 2025. Alzheimers Res Ther 8: 39. DOI: $10.1186 / \mathrm{s} 13195-016-0207-9$.

Cutler RG, Kelly J, Storie K, et al. 2004. Involvement of oxidative stress-induced abnormalities in ceramide and cholesterol metabolism in brain aging and Alzheimer's disease. Proc Natl Acad Sci USA 101(7): 2070-2075.

Czech C, Berndt P, Busch K, et al. 2012. Metabolite profiling of Alzheimer's disease cerebrospinal fluid. Plos One 7(2).

Dedeoglu A, Choi JK, Cormier K, Kowall NW, Jenkins BG. 2004. Magnetic resonance spectroscopic analysis of Alzheimer's disease mouse brain that express mutant human APP shows altered neurochemical profile. Brain Res 1012(1-2): 60-65.

Desai AK, Grossberg GT. 2005. Diagnosis and treatment of Alzheimer's disease. Neurology 64(12 Suppl 3):S34-S39.

Di Paolo G, Kim TW. 2011. Linking lipids to Alzheimer's disease: cholesterol and beyond. Nat Rev Neurosci 12(8): 284.

Dinkins MB, Dasgupta S, Wang GH, Zhu G, Bieberich E. 2014. Exosome reduction in vivo is associated with lower amyloid plaque load in the 5XFAD mouse model of Alzheimer's disease. Neurobiol Aging 35(8): 1792-1800.

Djelti F, Braudeau J, Hudry E, et al. 2015. CYP46A1 inhibition, brain cholesterol accumulation and neurodegeneration pave the way for Alzheimer's disease. Brain 138(Pt 8): 2383-2398. DOI: 10.1093/ brain/awv166.

Dobrowsky RT, Kamibayashi C, Mumby MC., Hannun YA. 1993. Ceramide activates heterotrimeric protein phosphatase-2a. J Biol Chem 268(21): 15523-15530.

Dong S, Duan Y, Hu Y, Zhao Z. 2012. Advances in the pathogenesis of Alzheimer's disease: a re-evaluation of amyloid cascade hypothesis. Transl Neurodegener 1(1): 18. DOI: 10.1186/ 2047-9158-1-18.

Farrer LA, Cupples LA, Haines JL, et al. 1997. Effects of age, sex, and ethnicity on the association between apolipoprotein $\mathrm{E}$ genotype and Alzheimer disease - A meta-analysis. Jama-J Am Med Assoc 278(16): 1349-1356.

Fehlbaum-Beurdeley P, Sol O, Desire L, et al. 2012. Validation of AclarusDx (TM), a blood-based transcriptomic signature for the diagnosis of Alzheimer's disease. J Alzheimers Dis 32(1): 169181.

Fiandaca MS, Mapstone ME, Cheema AK, Federoff HJ. 2014. The critical need for defining preclinical biomarkers in Alzheimer's disease. Alzheimers Dement 10(3 Suppl): S196-S212. DOI: 10.1016/j.jalz.2014.04.015.

Filippov V, Song MA, Zhang KL, et al. 2012. Increased ceramide in brains with Alzheimer's and other neurodegenerative diseases. $J$ Alzheimers Dis 29(3): 537-547. DOI: 10.3233/JAD2011-111202.

Foley P. 2010. Lipids in Alzheimer's disease: a century-old story. Biochim Biophys Acta 1801(8): 750-753. DOI: 10.1016/j. bbalip.2010.05.004.

Forster DM, James MF, Williams SR. 2012. Effects of Alzheimer's disease transgenes on neurochemical expression in the mouse brain determined by $1 \mathrm{H}$ MRS in vitro. Nmr in Biomedicine 25(1): $52-58$.

Fukuhara K, Ohno A, Ota Y, et al. 2013. NMR-based metabolomics of urine in a mouse model of Alzheimer's disease: identification of oxidative stress biomarkers. J Clin Biochem Nutr 52(2): 133-138.
Ghanbari H, Ghanbari K, Beheshti I, Munzar M, Vasauskas A, Averback P. 1998. Biochemical assay for AD7C-NTP in urine as an Alzheimer's disease marker. J Clin Lab Anal 12(5): 285 288.

Godzien J, Ciborowski M, Whiley L, Legido-Quigley C, Ruperez FJ, Barbas C. 2013. In-vial dual extraction liquid chromatography coupled to mass spectrometry applied to streptozotocin-treated diabetic rats. Tips and pitfalls of the method. J Chromatogr A 1304: 52-60. DOI: 10.1016/j.chroma.2013.07.029.

Gonzalez-Dominguez R, García-Barrera T, Gómez-Ariza J-L. 2012. Metabolomic approach to Alzheimer's disease diagnosis based on mass spectrometry. Chem Papers 66(9): 829-835. DOI: 10.2478/ s11696-012-0184-9.

Gonzalez-Dominguez R, Garcia A, Garcia-Barrera T, Barbas C, Gomez-Ariza JL. 2014a. Metabolomic profiling of serum in the progression of Alzheimer's disease by capillary electrophoresismass spectrometry. Electrophoresis 35(23): 3321-3330.

Gonzalez-Dominguez R, Garcia-Barrera T, Gomez-Ariza JL. 2014b. Combination of metabolomic and phospholipid-profiling approaches for the study of Alzheimer's disease. J Proteomics 104: 37-47. DOI: 10.1016/j.jprot.2014.01.014.

Gonzalez-Dominguez R, Garcia-Barrera T, Gomez-Ariza JL. 2014c. Metabolomic study of lipids in serum for biomarker discovery in Alzheimer's disease using direct infusion mass spectrometry. $J$ Pharm Biomed Anal 98: 321-326. DOI: 10.1016/j. jpba.2014.05.023.

Gonzalez-Dominguez R, Garcia-Barrera T, Vitorica J, Gomez-Ariza JL. 2014d. Region-specific metabolic alterations in the brain of the APP/PS1 transgenic mice of Alzheimer's disease. Bba-Mol Basis Dis 1842(12): 2395-2402.

Gonzalez-Dominguez R, García-Barrera T, Gómez-Ariza JL. 2014e. Using direct infusion mass spectrometry for serum metabolomics in Alzheimer's disease. Anal Bioanal Chem 406(28): 7137-7148. DOI: $10.1007 / \mathrm{s} 00216-014-8102-3$.

Gonzalez-Dominguez R, Garcia-Barrera T, Gomez-Ariza JL. 2015a. Application of a novel metabolomic approach based on atmospheric pressure photoionization mass spectrometry using flow injection analysis for the study of Alzheimer's disease. Talanta 131: 480-489. DOI: 10.1016/j.talanta.2014.07.075.

Gonzalez-Dominguez R, Garcia-Barrera T, Gomez-Ariza JL. 2015 b. Metabolite profiling for the identification of altered metabolic pathways in Alzheimer's disease. J Pharmaceut Biomed 107: 7581.

Gonzalez-Dominguez R, Garcia-Barrera T, Vitorica J, Gomez-Ariza JL. 2015c. Application of metabolomics based on direct mass spectrometry analysis for the elucidation of altered metabolic pathways in serum from the APP/PS1 transgenic model of Alzheimer's disease. J Pharmaceut Biomed 107: 378-385.

Gonzalez-Dominguez R, Garcia-Barrera T, Vitorica J, Gomez-Ariza JL. 2015d. Deciphering metabolic abnormalities associated with Alzheimer's disease in the APP/PS1 mouse model using integrated metabolomic approaches. Biochimie 110: 119-128.

Gonzalez-Dominguez R, Garcia-Barrera T, Vitorica J, Gomez-Ariza JL. 2015e. High throughput multiorgan metabolomics in the APP/ PS1 mouse model of Alzheimer's disease. Electrophoresis 36 (18): 2237-2249.

Gonzalez-Dominguez R, Garcia-Barrera T, Vitorica J, Gomez-Ariza JL. 2015f. Metabolomic investigation of systemic manifestations associated with Alzheimer's disease in the APP/PS1 transgenic mouse model. Mol Biosyst 11(9): 2429-2440.

Gonzalez-Dominguez R, Garcia-Barrera T, Vitorica J, Gomez-Ariza JL. 2015g. Metabolomic research on the role of interleukin-4 in Alzheimer's disease. Metabolomics 11(5): 1175-1183. 
Gonzalez-Dominguez R, Garcia-Barrera T, Vitorica J, Gomez-Ariza JL. 2015h. Metabolomic screening of regional brain alterations in the APP/PS1 transgenic model of Alzheimer's disease by direct infusion mass spectrometry. J Pharmaceut Biomed 102: 425-435.

Gonzalez-Dominguez R, Garcia-Barrera T, Vitorica J, Gomez-Ariza JL. 2015i. Metabolomics reveals significant impairments in the immune system of the APP/PS1 transgenic mice of Alzheimer's disease. Electrophoresis 36(4): 577-587.

Gonzalez-Dominguez R, Ruperez FJ, Garcia-Barrera T, Barbas C, Gomez-Ariza JL. 2016. Metabolomic-driven elucidation of serum disturbances associated with Alzheimer's disease and mild cognitive impairment. Curr Alzheimer Res 13(6): 641-653.

Graham SF, Chevallier OP, Roberts D, Holscher C, Elliott CT, Green BD. 2013a. Investigation of the human brain metabolome to identify potential markers for early diagnosis and therapeutic targets of Alzheimer's disease. Anal Chem 85(3): 1803-1811. DOI: $10.1021 / \mathrm{ac} 303163 \mathrm{f}$.

Graham SF, Holscher C, McClean P, Elliott CT, Green BD. 2013b. H1 NMR metabolomics investigation of an Alzheimer's disease (AD) mouse model pinpoints important biochemical disturbances in brain and plasma. Metabolomics 9(5): 974-983.

Graham SF, Holscher C, Green BD. 2014. Metabolic signatures of human Alzheimer's disease (AD): H-1 NMR analysis of the polar metabolome of post-mortem brain tissue. Metabolomics 10(4): 744-753.

Graham SF, Chevallier OP, Elliott CT, et al. 2015. Untargeted metabolomic analysis of human plasma indicates differentially affected Polyamine and L-Arginine metabolism in mild cognitive impairment subjects converting to Alzheimer's disease. Plos One 10(3).

Greenberg N, Grassano A, Thambisetty M, Lovestone S, LegidoQuigley C. 2009. A proposed metabolic strategy for monitoring disease progression in Alzheimer's disease. Electrophoresis 30 (7): 1235-1239.

Guan ZZ, Wang YA, Cairns NJ, Lantos PL, Dallner G, Sindelar PJ. 1999. Decrease and structural modifications of phosphatidylethanolamine plasmalogen in the brain with Alzheimer disease. $J$ Neuropath Exp Neur 58(7): 740-747.

Hampel H, Frank R, Broich K., et al. 2010. Biomarkers for Alzheimer's disease: academic, industry and regulatory perspectives. Nat Rev Drug Discov 9(7): 560-574. DOI: 10.1038/ $\operatorname{nrd} 3115$.

Han XL, Holtzman DM, McKeel DW. 2001. Plasmalogen deficiency in early Alzheimer's disease subjects and in animal models: molecular characterization using electrospray ionization mass spectrometry. J Neurochem 77(4): 1168-1180.

Han XL, Holtzman DM, McKeel DW, Kelley J, Morris JC. 2002. Substantial sulfatide deficiency and ceramide elevation in very early Alzheimer's disease: potential role in disease pathogenesis. $J$ Neurochem 82(4): 809-818.

Han X, Rozen S, Boyle SH, et al. 2011. Metabolomics in early Alzheimer's disease: identification of altered plasma sphingolipidome using shotgun lipidomics. Plos One 6(7): e21643. DOI: 10.1371/journal.pone.0021643.

Han XL, Rozen S, Boyle SH, et al. 2011. Metabolomics in early Alzheimer's disease: identification of altered plasma sphingolipidome using shotgun lipidomics. Plos One 6(7).

Hannun YA, Obeid LM. 2002. The ceramide-centric universe of lipidmediated cell regulation: stress encounters of the lipid kind. J Biol Chem 277(29): 25847-25850.

Harris JM, Thompson JC, Gall C, et al. 2015. Do NIA-AA criteria distinguish Alzheimer's disease from frontotemporal dementia? Alzheimers Dement 11(2): 207-215.
Hartmann T, Kuchenbecker J, Grimm MOW. 2007. Alzheimer's disease: the lipid connection. $J$ Neurochem 103: 159-170. DOI: 10.1111/j.1471-4159.2007.04715.x.

He XX, Huang Y, Li B, Gong CX, Schuchman EH. 2010. Deregulation of sphingolipid metabolism in Alzheimer's disease. Neurobiol Aging 31(3): 398-408.

Hebert LE, Weuve J, Scherr PA, Evans DA. 2013. Alzheimer disease in the United States (2010-2050) estimated using the 2010 census. Neurology 80(19): 1778-1783. DOI: 10.1212/ WNL.0b013e31828726f5.

Heinrich M, Wickel M, Schneider-Brachert W, et al. 1999. Cathepsin $\mathrm{D}$ targeted by acid sphingomyelinase-derived ceramide. Embo $J$ 18(19): 5252-5263.

Hirsch-Reinshagen V, Maia LF, Burgess BL, et al. 2005. The absence of ABCA1 decreases soluble ApoE levels but does not diminish amyloid deposition in two murine models of Alzheimer disease. $J$ Biol Chem 280(52): 43243-43256.

Holmes E, Nicholson JK. 2007. Human metabolic phenotyping and metabolome wide association studies. Ernst Schering Found Symp Proc (4): 227-249.

Hu LP, Browne ER, Liu T, Angel TE, Ho PC, Chan ECY. 2012. Metabonomic profiling of TASTPM transgenic Alzheimer's disease mouse model. J Proteome Res 11(12): 5903-5913.

Humpel C. 2011. Identifying and validating biomarkers for Alzheimer's disease. Trends Biotechnol 29(1): 26-32. DOI: 10.1016/j.tibtech.2010.09.007.

Hutter-Paier B, Huttunen HJ, Puglielli L, et al. 2010. The ACAT onhibitor CP-113, 818 markedly reduces amyloid pathology in a mouse model of Alzheimer's disease (vol 44, pg 227, 2004). Neuron 68(5): 1014. DOI: 10.1016/j.neuron.2010.11.028.

Hye A, Riddoch-Contreras J, Baird AL, et al. 2014. Plasma proteins predict conversion to dementia from prodromal disease. Alzheimers Dement 10(6): 799-807 e2. DOI: 10.1016/j. jalz.2014.05.1749.

Ibanez C, Simo C, Martin-Alvarez PJ, et al. 2012. Toward a predictive model of Alzheimer's disease progression using capillary electrophoresis-mass spectrometry metabolomics. Anal Chem 84(20): 8532-8540.

Ibanez C, Simo C, Barupal DK, et al. 2013. A new metabolomic workflow for early detection of Alzheimer's disease. $J$ Chromatogr A 1302: 65-71. DOI: 10.1016/j.chro ma.2013.06.005.

Inoue K, Tsutsui H, Akatsu H, et al. 2013. Metabolic profiling of Alzheimer's disease brains. Sci Rep-Uk 3.

James BD, Leurgans SE, Hebert LE, Scherr PA, Yaffe K, Bennett DA. 2014. Contribution of Alzheimer disease to mortality in the United States. Neurology 82(12): 1045-1050.

Jana A, Pahan K. 2010. Fibrillar amyloid-beta-activated human astroglia kill primary human neurons via neutral sphingomyelinase: implications for Alzheimer's disease. J Neurosci 30(38): 12676-12689.

Janelidze S, Stomrud E, Palmqvist S, et al. 2016. Plasma betaamyloid in Alzheimer's disease and vascular disease. Sci Rep-Uk6.

Jick H, Zornberg GL, Jick SS, Seshadri S, Drachman DA. 2000. Statins and the risk of dementia. Lancet 356(9242): 16271631.

Jukarainen NM, Korhonen SP, Laakso MP, et al. 2008. Quantification of H-1 NMR spectra of human cerebrospinal fluid: a protocol based on constrained total-line-shape analysis. Metabolomics 4 (2): $150-160$.

Kaddurah-Daouk R, Rozen S, Matson W, et al. 2011. Metabolomic changes in autopsy-confirmed Alzheimer's disease. Alzheimers Dement 7(3): 309-317. 
Kaddurah-Daouk R, Zhu H, Sharma S, et al. 2013. Alterations in metabolic pathways and networks in Alzheimer's disease. Transl Psychiat 3. DOI: 10.1038/tp.2013.18.

Khan TK, Alkon DL. 2010. Early diagnostic accuracy and pathophysiologic relevance of an autopsy-confirmed Alzheimer's disease peripheral biomarker. Neurobiol Aging 31(6): 889-900. DOI: 10.1016/j.neurobiolaging.2008.07.010.

Kim J, Castellano JM, Jiang H, et al. 2009. Overexpression of lowdensity lipoprotein receptor in the brain markedly inhibits amyloid deposition and increases extracellular a beta clearance. Neuron 64(5): 632-644.

Kim M, Nevado-Holgado A, Whiley L, et al. 2016. Association between plasma ceramides and phosphatidylcholines and hippocampal brain volume in late onset Alzheimer's disease. $J$ Alzheimers Dis. DOI: 10.3233/JAD-160645.

Kimball BA, Wilson DA, Wesson DW. 2016a. Alterations of the volatile metabolome in mouse models of Alzheimer's disease. Sci Rep 6: 19495. DOI: 10.1038/srep19495.

Kimball BA, Wilson DA, Wesson DW. 2016b. Alterations of the volatile metabolome in mouse models of Alzheimer's disease. Sci Rep-Uk 6.

Kivipelto M, Helkala EL, Laakso MP, et al. 2002. Apolipoprotein E epsilon 4 allele, elevated midlife total cholesterol level, and high midlife systolic blood pressure are independent risk factors for late-life Alzheimer disease. Ann Intern Med 137(3): 149-155.

Klavins K, Koal T, Dallmann G, Marksteiner J, Kemmler G, Humpel C. 2015. The ratio of phosphatidylcholines to lysophosphatidylcholines in plasma differentiates healthy controls from patients with Alzheimer's disease and mild cognitive impairment. Alzheimer's Dement: Diagn Assess Dis Monit 1(3): 295-302. DOI: 0.1016/j.dadm.2015.05.003.

Klunk WE, Panchalingam K, Moossy J, Mcclure RJ, Pettegrew JW. 1992. N-Acetyl-L-Aspartate and other amino-acid metabolites in Alzheimers-disease brain- A preliminary proton nuclear-magnetic-resonance study. Neurology 42(8): 1578-1585.

Knopman DS, DeKosky ST, Cummings JL, et al. 2001. Practice parameter: diagnosis of dementia (an evidence-based review). Report of the Quality Standards Subcommittee of the American Academy of Neurology. Neurology 56(9): 1143-1153.

Koal T, Klavins K, Seppi D, Kemmler G, Humpel C. 2015. Sphingomyelin SM(d18:1/18:0) is significantly enhanced in cerebrospinal fluid samples dichotomized by pathological Amyloid-beta(42), Tau, and Phospho-Tau-181 Levels. J Alzheimers Dis 44(4): 1193-1201.

Kok E, Haikonen S, Luoto T, et al. 2009. Apolipoprotein E-dependent accumulation of Alzheimer disease-related lesions begins in Middle Age. Ann Neurol 65(6): 650-657.

Koldamova R, Staufenbiel M, Lefterov I. 2005. Lack of ABCA1 considerably decreases brain ApoE level and increases amyloid deposition in APP23 mice. J Biol Chem 280(52): 43224-43235.

Kork F, Holthues J, Hellweg R, et al. 2009. A possible new diagnostic biomarker in early diagnosis of Alzheimer's disease. Curr Alzheimer Res 6(6): 519-524.

Koudinov AR, Koudinova NV. 2001. Essential role for cholesterol in synaptic plasticity and neuronal degeneration. FASEB $J$ 15(8): 1858.

Kumar P, Dezso Z, MacKenzie C, et al. 2013. Circulating miRNA biomarkers for Alzheimer's disease. Plos One 8(7).

Kuo YM, Emmerling MR, Bisgaier CL, et al. 1998. Elevated lowdensity lipoprotein in Alzheimer's disease correlates with brain A beta 1-42 levels. Biochem Bioph Res Co 252(3): 711-715.
Laakso MP, Jukarainen NM, Vepsalainen J. 2015. Diagnosis of dementias by high-field H-1 MRS of cerebrospinal fluid. J Neurol Neurosur Ps 86(12): 1286-1290.

Lalande J, Halley H, Balayssac S, et al. 2014. H-1 NMR metabolomic signatures in five brain regions of the A beta PPswe Tg2576 mouse model of Alzheimer's disease at four ages. J Alzheimers Dis 39(1): 121-143.

Lambert JC, Schraen-Maschke S, Richard F, et al. 2009. Association of plasma amyloid beta with risk of dementia. The prospective Three-City Study. Neurology 73(11): 847-853.

Leidinger P, Backes C, Deutscher S, et al. 2013. A blood based 12miRNA signature of Alzheimer disease patients. Genome Biol 14 (7).

Li NJ, Liu WT, Li W, et al. 2010a. Plasma metabolic profiling of Alzheimer's disease by liquid chromatography/mass spectrometry. Clin Biochem 43(12): 992-997.

Li NJ, Liu WT, Li W, et al. 2010b. Plasma metabolic profiling of Alzheimer's disease by liquid chromatography/mass spectrometry. Clin Biochem 43(12): 992-997. DOI: 10.1016/j.clinbio chem.2010.04.072.

Liang N, Yan XZ, Zhou WX, et al. 2008. NMR-based metabonomic investigations into the metabolic profile of the senescenceaccelerated mouse. J Proteome Res 7(9): 3678-3686.

Liang Q, Liu H, Zhang TY, Jiang Y, Xing HT, Zhang AH. 2015. Metabolomics-based screening of salivary biomarkers for early diagnosis of Alzheimer's disease. Rsc Adv 5(116): 96074-96079.

Liang Q, Liu H, Li X, Zhang AH. 2016a. High-throughput metabolomics analysis discovers salivary biomarkers for predicting mild cognitive impairment and Alzheimer's disease. Rsc $A d v$ 6(79): 75499-75504.

Liang Q, Liu H, Zhang TY, Jiang Y, Xing HT, Zhang AH. $2016 \mathrm{~b}$. Discovery of serum metabolites for diagnosis of progression of mild cognitive impairment to Alzheimer's disease using an optimized metabolomics method. Rsc Adv 6(5): 3586-3591.

Lin AP, Shic F, Enriquez C, Ross BD. 2003. Reduced glutamate neurotransmission with Alzheimer's disease-An in vivo C-13 magnetic resonance spectroscopy study. Magn Reson Mater Phy 16(1): 29-42.

Lin SH, Liu HD, Kanawati B, et al. 2013. Hippocampal metabolomics using ultrahigh-resolution mass spectrometry reveals neuroinflammation from Alzheimer's disease in CRND8 mice. Anal Bioanal Chem 405(15): 5105-5117.

Lin SH, Kanawati B, Liu LF, et al. 2014. Ultrahigh resolution mass spectrometry-based metabolic characterization reveals cerebellum as a disturbed region in two animal models. Talanta 118: 4553.

Linetti A, Fratangeli A, Taverna E, et al. 2010. Cholesterol reduction impairs exocytosis of synaptic vesicles. J Cell Sci 123(4): 595605.

Liu CC, Kanekiyo T, Xu H, Bu GJ. 2013. Apolipoprotein E and Alzheimer disease: risk, mechanisms and therapy. Nat Rev Neurol 9(4): 184

Lopez OL, Kuller LH, Mehta PD, et al. 2008. Plasma amyloid levels and the risk of AD in normal subjects in the Cardiovascular Health Study. Neurology 70(19): 1664-1671.

Lozano J, Berra E, Municio MM, et al. 1994. Protein-Kinase-C-Zeta Isoform is critical for Kappa-B-dependent promoter activation by Sphingomyelinase. J Biol Chem 269(30): 19200-19202.

Lundstrom SL, Yang HQ, Lyutvinskiy Y, et al. 2014. Blood plasma IgG Fc glycans are significantly altered in Alzheimer's disease and progressive mild cognitive impairment. J Alzheimers Dis 38 (3): $567-579$. 
Lutjohann D, Meichsner S, Pettersson H. 2012. Lipids in Alzheimer's disease and their potential for therapy. Clin Lipidol 7(1): 65-78.

Mapstone M, Cheema AK, Fiandaca MS, et al. 2014a. Plasma phospholipids identify antecedent memory impairment in older adults. Nat Med 20(4): 415-418. DOI: 10.1038/nm.3466.

Marjanska M, Curran GL, Wengenack TM, et al. 2005. Monitoring disease progression in transgenic mouse models of Alzheimer's disease with proton magnetic resonance spectroscopy. Proc Natl Acad Sci USA 102(33): 11906-11910.

Marksteiner J, Kemmler G, Weiss EM, et al. 2011. Five out of 16 plasma signaling proteins are enhanced in plasma of patients with mild cognitive impairment and Alzheimer's disease. Neurobiol Aging 32(3): 539-540. DOI: $10.1016 / \mathrm{j}$.neurobiolag ing.2009.03.011.

Mayeux R, Honig LS, Tang MX, et al. 2003. Plasma A beta 40 and A beta 42 and Alzheimer's disease - Relation to age, mortality, and risk. Neurology 61(9): 1185-1190.

McKhann GM, Knopman DS, Chertkow H, et al. 2011. The diagnosis of dementia due to Alzheimer's disease: recommendations from the National Institute on Aging-Alzheimer's Association workgroups on diagnostic guidelines for Alzheimer's disease. Alzheimers Dement 7(3): 263-269.

Merrill AH Jr., Schmelz EM, Dillehay DL, et al. 1997. Sphingolipids - The enigmatic lipid class: biochemistry, physiology, and pathophysiology. Toxicol Appl Pharmacol 142(1): 208-225. DOI: 10.1006/taap.1996.8029.

Mielke MM, Zandi PP, Sjogren M, et al. 2005. High total cholesterol levels in late life associated with a reduced risk of dementia. Neurology 64(10): 1689-1695.

Mielke MM, Bandaru VVR, Haughey NJ, et al. 2012. Serum ceramides increase the risk of Alzheimer disease. The Women's Health and Aging Study II. Neurology 79(7): 633-641.

Miller BL, Moats RA, Shonk T, Ernst T, Woolley S, Ross BD. 1993. Alzheimer-disease-Depiction of increased cerebral myoinositol with proton Mr spectroscopy. Radiology 187(2): 433-437.

Mohanakrishnan P, Fowler AH, Vonsattel JP, et al. 1995. An in-vitro H-1 nuclear-magnetic-resonance study of the temporoparietal cortex of Alzheimer brains. Exp Brain Res 102(3): 503-510.

Mohanakrishnan P, Fowler AH, Vonsattel JP, et al. 1997. Regional metabolic alterations in Alzheimer's disease: an in vitro $\mathrm{H}-1$ NMR study of the hippocampus and cerebellum. $J$ Gerontol aBiol 52(2): B111-B117.

Motsinger-Reif AA, Zhu H, Kling MA, et al. 2013. Comparing metabolomic and pathologic biomarkers alone and in combination for discriminating Alzheimer's disease from normal cognitive aging. Acta Neuropathol Commun 1 28. DOI: 10.1186/2051-5960-1-28.

Mulder C, Wahlund LO, Teerlink T, et al. 2003. Decreased lysophosphatidylcholine/phosphatidylcholine ratio in cerebrospinal fluid in Alzheimer's disease. J Neural Transm 110(8): 949955.

Myint KT, Aoshima K, Tanaka S, Nakamura T, Oda Y. 2009. Quantitative profiling of polar cationic metabolites in human cerebrospinal fluid by reversed-phase nanoliquid chromatography/mass spectrometry. Anal Chem 81(3): 1121-1129. DOI: $10.1021 / \mathrm{ac} 802259 \mathrm{r}$.

Nicholson JK, Holmes E, Lindon JC. Chapter 1-Metabonomics and metabolomics techniques and their applications in mammalian systems. In: The Handbook of metabonomics and metabolomics. Amsterdam: Elsevier Science B.V., 2007, pp 1-33.

Nitsch RM, Blusztajn JK, Pittas AG, Slack BE, Growdon JH, Wurtman RJ. 1992. Evidence for a membrane defect in Alzheimerdisease brain. Proc Natl Acad Sci USA 89(5): 1671-1675.
O’Bryant SE, Xiao G, Barber R, et al. 2010. A serum protein-based algorithm for the detection of Alzheimer disease. Arch Neurol 67 (9): 1077-1081. DOI: 10.1001/archneurol.2010.215.

O'Bryant SE, Edwards M, Johnson L, et al. 2016. A blood screening test for Alzheimer's disease. Alzheimers Dement (Amst) 3: 83-90. DOI: 10.1016/j.dadm.2016.06.004.

Ohanian J, Ohanian V. 2001. Sphingolipids in mammalian cell signalling. Cell Mol Life Sci 58(14): 2053-2068.

Oresic M, Hyotylainen T, Herukka SK, et al. 2011. Metabolome in progression to Alzheimer's disease. Transl Psychiat 1.

Orešič M, Anderson G, Mattila I, et al. 2018. Targeted serum metabolite profiling identifies metabolic signatures in patients with Alzheimer's disease, normal pressure hydrocephalus and brain tumor. Front Neurosci 11(747). DOI: 10.3389/ fnins.2017.00747.

Paglia G, Stocchero M, Cacciatore S, et al. 2016. Unbiased metabolomic investigation of Alzheimer's disease brain points to dysregulation of mitochondrial aspartate metabolism. $J$ Proteome Res 15(2): 608-618. DOI: 10.1021/acs.jproteo me.5b01020.

Pan XB, Bin Nasaruddin M, Elliott CT, et al. 2016. Alzheimer's disease-like pathology has transient effects on the brain and blood metabolome. Neurobiol Aging 38: 151-163.

Pedrini S, Carter TL, Prendergast G, Petanceska S, Ehrlich ME, Gandy S. 2005. Modulation of statin-activated shedding of Alzheimer APP ectodomain by ROCK. Plos Med 2(1): 69-78.

Peng J, Guo K, Xia JG, et al. 2014. Development of Isotope labeling liquid chromatography mass spectrometry for mouse urine metabolomics: quantitative metabolomic study of transgenic mice related to Alzheimer's disease. J Proteome Res 13(10): 4457-469.

Pettegrew JW, Panchalingam K, Hamilton RL, McClure RJ. 2001. Brain membrane phospholipid alterations in Alzheimer's disease. Neurochem Res 26(7): 771-782.

Piro JR, Benjamin DI, Duerr JM, et al. 2012. A dysregulated endocannabinoid-eicosanoid network supports pathogenesis in a mouse model of Alzheimer's disease. Cell Rep 1(6): 617-623.

Prasad MR, Lovell MA, Yatin M, Dhillon H, Markesbery WR. 1998. Regional membrane phospholipid alterations in Alzheimer's disease. Neurochem Res 23(1): 81-88.

Proitsi P, Lupton MK, Velayudhan L, et al. 2014. Genetic predisposition to increased blood cholesterol and triglyceride lipid levels and risk of Alzheimer disease: a Mendelian randomization analysis. PLoS Med 11(9): e1001713. DOI: 10.1371/journal.pmed.1001713.

Proitsi P, Kim M, Whiley L, et al. 2015. Plasma lipidomics analysis finds long chain cholesteryl esters to be associated with Alzheimer's disease. Transl Psychiatr 5: e494. DOI: 10.1038/ tp.2014.127.

Proitsi P, Kim M, Whiley L, et al. 2017. Association of blood lipids with Alzheimer's disease: A comprehensive lipidomics analysis. Alzheimers Dement 13(2): 140-151. DOI: 10.1016/j. jalz.2016.08.003.

Psychogios N, Hau DD, Peng J, et al. 2011. The human serum metabolome. Plos One 6(2): e16957. DOI: 10.1371/journal. pone.0016957.

Puglielli L, Konopka G, Pack-Chung E, et al. 2001. Acyl-coenzyme A : cholesterol acyltransferase modulates the generation of the amyloid beta-peptide. Nat Cell Biol 3(10): 905-912.

Puglielli L, Ellis BC, Saunders AJ, Kovacs DM. 2003. Ceramide stabilizes beta-site amyloid precursor protein-cleaving enzyme 1 and promotes amyloid beta-peptide biogenesis. J Biol Chem 278 (22): 19777-19783. 
Raúl G-D, Francisco Javier R, Tamara G-B, Coral B, José Luis G-A. 2016. Metabolomic-driven elucidation of serum disturbances associated with Alzheimer's disease and mild cognitive impairment. Curr Alzheimer Res 13(6): 641-653. DOI: 10.2174/ 1567205013666160129095138.

Ray S, Britschgi M, Herbert C, et al. 2007a. Classification and prediction of clinical Alzheimer's diagnosis based on plasma signaling proteins. Nat Med 13(11): 1359-1362.

Ray S, Britschgi M, Herbert C, et al. 2007b. Classification and prediction of clinical Alzheimer's diagnosis based on plasma signaling proteins. Nat Med 13(11): 1359-1362. DOI: 10.1038/nm1653.

Reitz C. 2012. Alzheimer's disease and the amyloid cascade hypothesis: a critical review. Int $J$ Alzheimers Dis 2012: 369808. DOI: 10.1155/2012/369808.

Reitz C, Tang MX, Luchsinger J, Mayeux R. 2004. Relation of plasma lipids to Alzheimer disease and vascular dementia. Arch NeurolChicago 61(5): 705-714.

Roberts LD, Souza AL, Gerszten RE, Clish CB. 2012. Targeted metabolomics. Curr Protoc Mol Biol 2(Chapter 30, Unit 30): 124. DOI: $10.1002 / 0471142727 . \mathrm{mb3002s} 98$.

Ryman DC, Acosta-Baena N, Aisen PS, et al. 2014. Symptom onset in autosomal dominant Alzheimer disease: a systematic review and meta-analysis. Neurology 83(3): 253-260.

Salek RM, Xia J, Innes A, et al. 2010. A metabolomic study of the CRND8 transgenic mouse model of Alzheimer's disease. Neurochem Int 56(8): 937-947.

Sato Y, Nakamura T, Aoshima K, Oda Y. 2010. Quantitative and wide-ranging profiling of phospholipids in human plasma by twodimensional liquid chromatography/mass spectrometry. Anal Chem 82(23): 9858-9864.

Sato Y, Suzuki I, Nakamura T, Bernier F, Aoshima K, Oda Y. 2012. Identification of a new plasma biomarker of Alzheimer's disease using metabolomics technology. J Lipid Res 53(3): 567-576. DOI: $10.1194 /$ jlr.M022376.

Satoi H, Tomimoto H, Ohtani R, et al. 2005. Astroglial expression of ceramide in Alzheimer's disease brains: a role during neuronal apoptosis. Neuroscience 130(3): 657-666.

Schuff N, Amend D, Ezekiel F, et al. 1997. Changes of hippocampal $\mathrm{N}$-acetyl aspartate and volume in Alzheimer's disease - A proton MR spectroscopic imaging and MRI study. Neurology 49(6): 1513-1521.

Sepehrnia B, Kamboh MI, Adamscampbell LL, et al. 1989. Geneticstudies of human apolipoproteins.10. The effect of the apolipoprotein-E polymorphism on quantitative levels of lipoproteins in Nigerian blacks. Am J Hum Genet 45(4): 586-591.

Sharman MJ, Shui GH, Fernandis AZ, et al. 2010. Profiling brain and plasma lipids in human APOE epsilon 2, epsilon 3, and epsilon 4 knock-in mice using electrospray ionization mass spectrometry. $J$ Alzheimers Dis 20(1): 105-111.

Shonk TK, Moats RA, Gifford P, et al. 1995. Probable Alzheimerdisease-Diagnosis with proton Mr spectroscopy. Radiology 195 (1): $65-72$.

Simons M, Keller P, De Strooper B, Beyreuther K, Dotti CG, Simons K. 1998. Cholesterol depletion inhibits the generation of betaamyloid in hippocampal neurons. Proc Natl Acad Sci USA 95(11): 6460-6464.

Slominski A, Wortsman J. 2000. Neuroendocrinology of the skin. Endocr Rev 21(5): 457-487. DOI: 10.1210/edrv.21.5.0410.

Slominski AT, Zmijewski MA, Skobowiat C, Zbytek B, Slominski RM, Steketee JD. 2012. Sensing the environment: regulation of local and global homeostasis by the skin neuroendocrine system. Adv Anat Embryol Cell Biol 212: v-115.
Snowden SG, Ebshiana AA, Hye A, et al. 2017. Association between fatty acid metabolism in the brain and Alzheimer disease neuropathology and cognitive performance: A nontargeted metabolomic study. PLoS Med 14(3): e1002266. DOI: 10.1371/journal.pmed.1002266.

Snyder HM, Carrillo MC, Grodstein F, et al. 2014. Developing novel blood-based biomarkers for Alzheimer's disease. Alzheimers Dement 10(1): 109-114.

Soares HD, Chen Y, Sabbagh M, Roher A, Schrijvers E, Breteler M. 2009. Identifying early markers of Alzheimer's disease using quantitative multiplex proteomic immunoassay panels. Ann N Y Acad Sci 1180: 56-67. DOI: 10.1111/j.1749-6632.2009. 05066.x.

Son HH, Lee DY, Seo HS, et al. 2016. Hair sterol signatures coupled to multivariate data analysis reveal an increased 7beta-hydroxycholesterol production in cognitive impairment. J Steroid Biochem Mol Biol 155(Pt A): 9-17. DOI: 10.1016/j. jsbmb.2015.09.024.

Sparks DL, Scheff SW, Hunsaker JC 3rd, Liu H, Landers T, Gross DR. 1994. Induction of Alzheimer-like beta-amyloid immunoreactivity in the brains of rabbits with dietary cholesterol. Exp Neurol 126(1): 88-94. DOI: 10.1006/exnr.1994.1044.

Spiegel S, Milstien S. 1995. Sphingolipid metabolites-Members of a new class of lipid 2nd-messengers. J Membrane Biol 146(3): 225-237.

Spiegel S, Milstien S. 2002. Sphingosine 1-phosphate, a key cell signaling molecule. J Biol Chem 277(29): 25851-25854.

Stokes CE, Hawthorne JN. 1987. Reduced phosphoinositide concentrations in anterior temporal cortex of Alzheimer-diseased brains. J Neurochem 48(4): 1018-1021.

Tabert MH, Liu X, Doty RL, et al. 2005. A 10-item smell identification scale related to risk for Alzheimer's disease. Ann Neurol 58(1): 155-160. DOI: 10.1002/ana.20533.

Tajima Y, Ishikawa M, Maekawa K, et al. 2013. Lipidomic analysis of brain tissues and plasma in a mouse model expressing mutated human amyloid precursor protein/tau for Alzheimer's disease. Lipids Health Dis 12.

Tan L, Yu JT, Liu QY, et al. 2014. Circulating miR-125b as a biomarker of Alzheimer's disease. J Neurol Sci 336(1-2): $52-56$.

Tan ZS, Seshadri S, Beiser A, et al. 2003. Plasma total cholesterol level as a risk factor for Alzheimer disease-The Framingham study. Arch Intern Med 163(9): 1053.

Tang Z, Liu LF, Li YL, et al. 2016. Urinary metabolomics reveals alterations of aromatic amino acid metabolism of Alzheimer's disease in the transgenic CRND8 mice. Curr Alzheimer Res 13(7): 764-776.

Thies W, Bleiler L, Assoc As. 2013 Alzheimer's disease facts and figures Alzheimer's Association. Alzheimers Dement 9(2): 208245. DOI: $10.1016 /$ j.jalz.2013.02.003.

Toledo JB, Shaw LM, Trojanowski JQ. 2013. Plasma amyloid beta measurements-A desired but elusive Alzheimer's disease biomarker. Alzheimers Res Ther 5(2).

Toledo JB, Arnold M, Kastenmuller G, et al. 2017. Metabolic network failures in Alzheimer's disease-A biochemical road map. Alzheimers Dement. DOI: 10.1016/j.jalz.2017.01.020.

Trushina E, Nemutlu E, Zhang S, et al. 2012. Defects in mitochondrial dynamics and metabolomic signatures of evolving energetic stress in mouse models of familial Alzheimer's disease. Plos One $7(2)$.

Trushina E, Dutta T, Persson XM, Mielke MM, Petersen RC. 2013a. Identification of altered metabolic pathways in plasma and CSF in mild cognitive impairment and Alzheimer's disease using 
metabolomics. Plos One 8(5): e63644. DOI: 10.1371/journal. pone. 0063644 .

Trushina E, Dutta T, Persson XMT, Mielke MM, Petersen RC. 2013b. Identification of altered metabolic pathways in plasma and CSF in mild cognitive impairment and Alzheimer's disease using metabolomics. Plos One 8(6).

Trushina E, Mielke MM. 2014. Recent advances in the application of metabolomics to Alzheimer's disease. Biochim Biophys Acta 1842(8): 1232-1239. DOI: 10.1016/j.bbadis.2013.06.014.

Tsuruoka M, Hara J, Hirayama A, et al. 2013. Capillary electrophoresis-mass spectrometry-based metabolome analysis of serum and saliva from neurodegenerative dementia patients. Electrophoresis 34(19): 2865-2872.

Vetrivel KS, Thinakaran G. 2010. Membrane rafts in Alzheimer's disease beta-amyloid production. Bba-Mol Cell Biol L 1801(8): 860-867.

von Kienlin M, Kunnecke B, Metzger F, et al. 2005. Altered metabolic profile in the frontal cortex of PS2APP transgenic mice, monitored throughout their life span. Neurobiol Dis 18(1): 32-39.

Vos JP, Lopes-Cardozo M, Gadella BM. 1994. Metabolic and functional aspects of sulfogalactolipids. Biochim Biophys Acta 1211(2): 125-149.

Voyle N, Kim M, Proitsi P, et al. 2016. Blood metabolite markers of neocortical amyloid-beta burden: discovery and enrichment using candidate proteins. Transl Psychiatry 6: e719. DOI: 10.1038/ tp.2015.205.

Wahrle S, Das P, Nyborg AC, et al. 2002. Cholesterol-dependent gamma-secretase activity in buoyant cholesterol-rich membrane microdomains. Neurobiol Dis 9(1): 11-23.

Wahrle SE, Jiang H, Parsadanian M, et al. 2005. Deletion of Abca1 increases A beta deposition in the PDAPP transgenic mouse model of Alzheimer disease. J Biol Chem 280(52): 43236-43242.

Walter A, Korth U, Hilgert M, et al. 2004. Glycerophosphocholine is elevated in cerebrospinal fluid of Alzheimer patients. Neurobiol Aging 25(10): 1299-1303.

Wang G, Zhou Y, Huang FJ, et al. 2014. Plasma metabolite profiles of Alzheimer's disease and mild cognitive impairment. J Proteome Res 13(5): 2649-2658.

Wang HL, Lian KQ, Han B, et al. 2014. Age-related alterations in the metabolic profile in the hippocampus of the senescenceaccelerated mouse prone 8: a spontaneous Alzheimer's disease mouse model. J Alzheimers Dis 39(4): 841-848.

Want EJ, Wilson ID, Gika H, et al. 2010. Global metabolic profiling procedures for urine using UPLC-MS. Nat Protoc 5(6): 10051018.

Wells K, Farooqui AA, Liss L, Horrocks LA. 1995. Neural membrane phospholipids in Alzheimer disease. Neurochem Res 20(11): 1329-1333.
Wengenack TM, Whelan S, Curran GL, Duff KE, Poduslo JF. 2000. Quantitative histological analysis of amyloid deposition in Alzheimer's double transgenic mouse brain. Neuroscience 101 (4): 939-944.

Whiley L, Godzien J, Ruperez FJ, Legido-Quigley C, Barbas C. 2012. In-vial dual extraction for direct LC-MS analysis of plasma for comprehensive and highly reproducible metabolic fingerprinting. Anal Chem 84(14): 5992-5999. DOI: 10.1021/ ac300716u.

Whiley L, Sen A, Heaton J, et al. 2014. Evidence of altered phosphatidylcholine metabolism in Alzheimer's disease. Neurobiol Aging 35(2): 271-278.

Whitmer RA, Sidney S, Selby J, Johnston SC, Yaffe K. 2005. Midlife cardiovascular risk factors and risk of dementia in late life. Neurology 64(2): 277-281.

Wilson I. 2011. Global metabolic profiling (metabonomics/metabolomics) using dried blood spots: advantages and pitfalls. Bioanalysis 3(20): 2255-2257.

Wishart DS, Knox C, Guo AC, et al. 2009. HMDB: a knowledgebase for the human metabolome. Nucleic Acids Res 37(Database issue): D603-D610. DOI: 10.1093/nar/gkn810.

Wolozin B, Wang SW, Li NC, Lee A, Lee TA, Kazis LE. 2007. Simvastatin is associated with a reduced incidence of dementia and Parkinson's disease. Bmc Med 5.

Woo DC, Lee SH, Lee DW, et al. 2010. Regional metabolic alteration of Alzheimer's disease in mouse brain expressing mutant human APP-PS1 by H-1 HR-MAS. Behav Brain Res 211(1): $125-131$.

Wood PL, Barnette BL, Kaye JA, Quinn JF, Woltjer RL. 2015. Non-targeted lipidomics of CSF and frontal cortex grey and white matter in control, mild cognitive impairment, and Alzheimer's disease subjects. Acta Neuropsychiatr 27(5): 270 278.

Wood PL, Locke VA, Herling P, et al. 2016. Targeted lipidomics distinguishes patient subgroups in mild cognitive impairment (MCI) and late onset Alzheimer's disease (LOAD). BBA Clinical 5: 25-28. DOI: 10.1016/j.bbacli.2015.11.004.

Wu JF, Fu B, Lei HH, Tang HR, Wang YL. 2016. Gender differences of peripheral plasma and liver metabolic profiling in App/Ps1 transgenic ad mice. Neuroscience 332: 160-169.

Xu JS, Begley P, Church SJ, et al. 2016. Graded perturbations of metabolism in multiple regions of human brain in Alzheimer's disease: snapshot of a pervasive metabolic disorder. Bba-Mol Basis Dis 1862(6): 1084-1092.

Zheng JM, Dixon RA, Li L. 2012. Development of Isotope labeling LC-MS for human salivary metabolomics and application to profiling metabolome changes associated with mild cognitive impairment. Anal Chem 84(24): 10802-10811.

Cite this article as: Kim M, Legido-Quigley C. 2018. Small molecule biomarkers in Alzheimer's disease. OCL 25(4): D404. 